\title{
Structure and chemistry of liquid Al-Cu alloys: molecular dynamics study versus thermodynamics- based modelling
}

\author{
Marcela E. Trybula ${ }^{1,2, \star}$ (1), Przemysław W. Szafrański ${ }^{3}$, and Pavel A. Korzhavyi ${ }^{2}$ \\ ${ }^{1}$ Institute of Metallurgy and Materials Science Polish Academy of Sciences, 30-059 Kraków, Poland \\ ${ }^{2}$ Department of Materials Science and Engineering, KTH Royal Institute of Technology, 100-44 Stockholm, Sweden \\ ${ }^{3}$ Jagiellonian University Medical College, 30-688 Kraków, Poland
}

Received: 17 September 2017

Accepted: 5 February 2018

Published online:

26 February 2018

(C) The Author(s) 2018. This article is an open access publication

\begin{abstract}
Classical molecular dynamics simulations, employing a modified embedded atom model (MEAM) parametrization recently developed by Trybula, have been performed and combined with thermodynamics-based modelling for weakly interacting compound-forming molten alloys, to investigate the structure and chemistry of liquid $\mathrm{Al}-\mathrm{Cu}$ alloys over a broad $\mathrm{Cu}$ concentration range. The compound-forming model (CFM) based on experimental thermodynamic data revealed the importance of the $\mathrm{Al}_{2} \mathrm{Cu}$ "associate" in the determination of transport properties such as diffusion and viscosity as well as confirmation of the compound formation ability with regard to the available experimental data. Adequately to this fact, molecular dynamics simulation results showed strong evidence of deviation from regular metallic solution resulting from a preponderance of chemical short-range ordering, expressed by Warren-Cowley parameter and increasing abundance of icosahedral motifs with increasing $\mathrm{Cu}$ content. In addition, their strong impact on mass transport properties as well as the excess entropy has been detected which exhibits nonlinear compositional behaviour. Thus, we find that the Stokes-Einstein relation is unsuitable for atom transport properties determination at investigated $\mathrm{Cu}$ concentration range, while the Green-Kubo formalism can fully account for the experimentally observed physical phenomena. We obtain a compact and compatible view onto the structure and chemical behaviour, including atom kinetics and thermodynamics, of Al-Cu liquid alloys, which allowed us to find another hard-spherelike metallic system in which transport properties and thermodynamics are strongly affected by packing effects. The hybrid approach presented herein gave a broader and deeper look into the liquid state of the $\mathrm{Al}-\mathrm{Cu}$ alloys being missing in the literature.
\end{abstract}

Address correspondence to E-mail: trybulamarcela@wp.eu; m.trybula@imim.pl 


\section{Introduction}

Precise determination of structural and chemical properties of metallic systems is strenuous, and sometimes, even impossible, due to the technical limitations of the experimental set-up. However, a database limited to one property or even an incomplete experimental dataset can usually be sufficient to perform molecular dynamics simulations and/or use CALPHAD-type models enabling to quickly cover broad compositional dependence. Recent literature reports gave proof of MD simulations being sufficient, and then, such simulations have been extensively used for studies of structure, dynamics and thermodynamics of liquid and solid bulk materials [1-6]. Sometimes MD simulations are insufficient to obtain information that can be straightforwardly retrieved from CALPHAD calculations. This is a result of CALPHAD-type models' ability to give a first insight into the structure and atomic transport properties of a melt without any knowledge of semiempirical potentials [7-10].

At least four intermetallic phases $\left(\theta-\mathrm{Al}_{2} \mathrm{Cu}, \eta-\mathrm{AlCu}\right.$, $\gamma-\mathrm{Al}_{4} \mathrm{Cu}_{9}, \beta$-b.c.c.) exist in solid state of the $\mathrm{Al}-\mathrm{Cu}$ system [11], which makes it interesting according to experimental and computational contributions given in the literature [12-14]. In contrast, only a few reports are related to the liquid phase. Rybicki et al. [15] were the first to experimentally study the structure of the liquid $\mathrm{Al}_{83} \mathrm{Cu}_{17}$ alloy, observing how the atomic groups are linked to each other. Later, this melt was the subject of computational investigations, including ab initio molecular dynamics (AIMD) [16] and classical molecular dynamics studies [5], employing MEAM potentials [17]. Consequently, both studies revealed short-range order presence in the liquid state of the $\mathrm{Al}_{80} \mathrm{Cu}_{20}$ alloy, which is responsible for anomalous structural dynamics. Similarly to the $\mathrm{Al}_{80} \mathrm{Cu}_{20}$ melt investigations, analogous computational techniques have been used for liquid structure study at an another $\mathrm{Al}-\mathrm{Cu}$ alloy composition, i.e. $\mathrm{Al}_{60} \mathrm{Cu}_{40}$, including $\mathrm{AIMD}$ and CMD simulations performed by Wang et al. [18] and Dziedzic et al. [19], respectively.

Thermophysical properties of liquid Al-Cu alloys also caught scientific interest [19-22], including experimental and modelling contributions, which altogether build a solid background and open up a field for discussion of the new data presented in this paper. Schick et al. [20] experimentally determined viscosity for a series of liquid $\mathrm{Al}-\mathrm{Cu}$ alloy compositions, excluding only the liquid $\mathrm{Al}_{60} \mathrm{Cu}_{40}$ alloy, using a high-temperature oscillating-cup viscometer method and supplementing it with thermodynamicsbased modelling analyses. As a result, a pronounced maximum in viscosity was observed for $\mathrm{Al}-\mathrm{Cu}$ alloy composition close to intermetallic phases existing in the solid state of the Al-Cu system, which could suggest "associates" influence. This issue has not been discussed in the literature with regard to structure and diffusivity investigations. The latter ones include the determination of the self-diffusion coefficient of $\mathrm{Cu}$ and of the mutual diffusion coefficient using neutron scattering [21] or X-ray radiography [22] for liquid $\mathrm{Al}$-rich alloys, namely $\mathrm{Al}_{90} \mathrm{Cu}_{10}$, $\mathrm{Al}_{83} \mathrm{Cu}_{17}, \mathrm{Al}_{80} \mathrm{Cu}_{20}$ and $\mathrm{Al}_{75} \mathrm{Cu}_{25}$.

The "associate forming tendency" has been partially studied by Trybula et al. [23], using the free volume model (FVM), but this investigation provided only fragmentary insights into the structure and thermodynamics of $\mathrm{Al}-\mathrm{Cu}$ liquid alloys. Unfortunately, those results were not enough to fully describe the physical phenomena occurring in the liquid state of the Al-Cu alloys due to the FVM constraints [24]. Apart from that, no detailed study on the topology of local atom environment and its relationship with chemistry and atom kinetics has been given yet, which could play a vital role in the investigation of glass or crystal state stability. As it has been shown in a recent study on liquid $\mathrm{Al}-\mathrm{Zn}$ alloys [4], a combination of MD simulations with thermodynamics-based modelling can successfully account for experimental data and describe the relationship between the structure and thermophysical properties. One of the widely used thermodynamicsbased models is the quasi-chemical approximation [7], which can successfully reproduce experimental data for various liquid metallic alloys $[25,26]$.

In this work, we propose to combine molecular dynamics simulations with thermodynamics-based models to study the structure and chemistry of liquid $\mathrm{Al}-\mathrm{Cu}$ alloys. Furthermore, the results presented herein extend the applicability of the new modified embedded atom model (MEAM) parametrization established by Trybula [5] to Al-Cu alloys with higher $\mathrm{Cu}$ content. In this concept, we would like to initially compute properties that are available in the literature to check the validity of the MEAM potential. We then proceed to investigate the energetic 
stability of atomic clusters and their influence on kinetics and thermodynamics of $\mathrm{Al}-\mathrm{Cu}$ alloy liquid state. Structural characterization obtained by performing MD simulations concerns the analysis of local chemical surroundings of atoms, including the computation of a structure factor and pair distribution functions, which is then supplemented by 3D imaging of local atom topology. In addition, we search for a structure-dynamics-thermodynamics relationship by considering the universal scaling law [27] and extended Enskog collision frequency theory [28]. Finally, the main scope of the present work is building a bridge between MD-based simulations and CALPHAD-type modelling based on quasichemical approximation for a weakly compoundforming molten alloy [29] and tests it on liquid Al-Cu alloys that will be helpful in discussion of structure and chemistry of the Al-Cu system liquid state.

\section{Computational methods}

\section{Quasi-chemical approximation for weak compound-forming melt}

Within the compound formation model (CFM), the presence of an appropriate chemical compound of $A_{m} B_{n}$ type ( $m$ and $n$ are integer numbers) is considered for a binary system, A-B. $A_{m} B_{n}$ type corresponds to one of the intermetallic phases occurring in the solid state, or it is just a hypothetical one. The complete mathematical formalism of the CFM approach can be found elsewhere $[7,30]$.

The principal thermodynamic quantity is Gibbs free energy of mixing, $G_{\text {mix }}$, which has the form:

$$
\begin{aligned}
G_{\text {mix }}= & k_{\mathrm{B}} T\left[\left(\frac{W}{k_{\mathrm{B}} T}\right) \cdot C(1-C)+\left(\frac{\Delta W_{\mathrm{AB}}}{k_{\mathrm{B}} T}\right) \cdot \Phi_{A B}(C)\right. \\
& \left.+\left(\frac{\Delta W_{\mathrm{AA}}}{k_{\mathrm{B}} T}\right) \cdot \Phi_{\mathrm{AA}}(C)+\left(\frac{\Delta W_{\mathrm{BB}}}{k_{\mathrm{B}} T}\right) \cdot \Phi_{\mathrm{BB}}(C)\right] .
\end{aligned}
$$

Such form of $G_{\text {mix }}$ is obtained when standard thermodynamic relations are applied, and some algebraic rearrangements are made according to a receipt previously used by Novakovic et al. [10, 26] or Trybula et al. [9]. $\Phi_{i j}(i, j=A, B)$ are concentration functions depending on $m$ and $n$ values, $C$ is concentration of one component, $k_{B}$ is the Boltzmann constant, and $T$ is absolute temperature. $W, \Delta W_{\mathrm{AB}}, \Delta W_{\mathrm{AA}}, \Delta W_{\mathrm{BB}}$ are energy-pair parameters optimized by utilizing the least-squares method and fitting the modelled $G_{\text {mix }}$ to experimental one. Different expressions can be devised for the computation of the concentration functions in relevance to the assumed type of clusters existing in the liquid state. In present consideration, we examined two variants of $\Phi_{i j}$ functions, the first corresponds to the $\mathrm{Al}_{2} \mathrm{Cu}$ compound, while the latter variant is the $\mathrm{Al}_{2} \mathrm{Cu}_{3}$ phase. Therefore, $\Phi_{i j}$ functions are formulated as follows [31]:

1. $m=1$ and $n=2$ for $\mathrm{Al}_{2} \mathrm{Cu}$ compound:

$$
\begin{aligned}
\Phi_{\mathrm{AB}} & =\frac{1}{6}(1-C)+(1-C)^{2}-\frac{5}{3}(1-C)^{3}+\frac{1}{2}(1-C)^{4} ; \\
\Phi_{\mathrm{AA}} & =0 ; \\
\Phi_{\mathrm{BB}} & =-\frac{1}{4}(1-C)+\frac{1}{2}(1-C)^{2}-\frac{1}{4}(1-C)^{4}
\end{aligned}
$$

2. $m=2$ and $n=3$ for $\mathrm{Al}_{2} \mathrm{Cu}_{3}$ clusters:

$$
\begin{aligned}
\Phi_{\mathrm{AB}}= & \frac{13}{420}(1-C)+\frac{2}{3}(1-C)^{3}-\frac{3}{2}(1-C)^{4} \\
& +\frac{2}{3}(1-C)^{6}-\frac{5}{7}(1-C)^{7}+\frac{1}{4}(1-C)^{8} ; \\
\Phi_{\mathrm{AA}}= & -\frac{53}{840}(1-C)+\frac{2}{3}(1-C)^{3}-\frac{5}{4}(1-C)^{4} \\
& -(1-C)^{6}+\frac{4}{7}(1-C)^{7}-\frac{1}{8}(1-C)^{8} ; \\
\Phi_{\mathrm{BB}}= & \frac{23}{280}(1-C)-\frac{1}{2}(1-C)^{4}+\frac{2}{5}(1-C)^{6} \\
& +\frac{1}{7}(1-C)^{7}-\frac{1}{8}(1-C)^{8} .
\end{aligned}
$$

The aforementioned functions can also be used for examining the chemical short-range order in a melt. The first structure index, that is directly calculated from the CFM formalism and linked to BhatiaThornton (B-Th) theory [32], is the concentration fluctuation function at the long wavelength limit, $\mathrm{S}_{\mathrm{CC}}(0)$. It is an indicative of chemical short-range order, and for a sub-regular metallic system it is formulated as follows:

$$
\begin{aligned}
\mathrm{S}_{\mathrm{cc}}(0)= & k_{\mathrm{B}} T\left[\left(\frac{W}{k_{\mathrm{B}} T}\right) \cdot C(1-C)+\left(\frac{\Delta W_{A B}}{k_{\mathrm{B}} T}\right) \cdot \Phi_{\mathrm{AB}}\right. \\
& \left.+\left(\frac{\Delta W_{\mathrm{AA}}}{k_{\mathrm{B}} T}\right) \cdot \Phi_{\mathrm{AA}}+\left(\frac{\Delta W_{\mathrm{BB}}}{k_{\mathrm{B}} T}\right) \cdot \Phi_{\mathrm{BB}}\right],
\end{aligned}
$$


while for ideal solution, $S_{\mathrm{cc}}(0, \mathrm{id})$ has the form of:

$S_{\mathrm{CC}}(0, \mathrm{id})=C(1-C)$.

The second indicator of short-range order (SRO) in a molten alloy is the Warren-Cowley parameter $\alpha_{\text {tot }}$ [33], quantifying chemical SRO within the first coordination shell and it is written:

$\alpha_{\mathrm{tot}}=\frac{M-1}{[1-M \cdot(Z-1)]}$,

where $Z$ is the coordination number and $M$ is the $S_{\mathrm{cc}}(0) /\left(S_{\mathrm{cc}}(0, \mathrm{id})\right)$ ratio. A melt has a compound formation tendency for which the $M$ value is lower than unity [34].

\section{Molecular dynamics simulations}

A recent parametrization of the modified embedded atom model (MEAM), given by Trybula [5] for liquid $\mathrm{Al}_{80} \mathrm{Cu}_{20}$ alloys, has been used for the investigation of $\mathrm{Al}_{1-\mathrm{x}} \mathrm{Cu}_{\mathrm{x}}(x=10,30,40$ and 50 at $\%)$ alloys properties by means of molecular dynamics simulations (MD). A consistent and compact description of liquid $\mathrm{Al}_{80-}$ $\mathrm{Cu}_{20}$ alloys' properties was obtained in reference to the previous ab initio molecular dynamics [16] (AIMD) and experimental [20, 22, 35] results. Herein, we validate this MEAM parametrization for structure and transport properties investigations over a broad $\mathrm{Cu}$ concentration range. All MD simulations have been performed using the LAMMPS code [36] and carried out using the Verlet algorithm with a time step of 1.5 fs. Cubic box with a total number of 1372 atoms was built, and periodic boundary conditions in three directions were imposed for each $\mathrm{Al}-\mathrm{Cu}$ composition investigated. Randomly oriented atoms in the simulation box were initially heated up to $2500 \mathrm{~K}$ and thermalized during 100 ps. Pressure, volume and temperature of each sample during quenching were monitored to reproduce experimental densities [37] at each temperature investigated $(T=1073,1173$, 1223, 1345 and $1523 \mathrm{~K}$ ). Before structural and dynamic properties determination, each sample was thermalized during $20 \mathrm{ps}$ and the final simulations were continued for $500 \mathrm{ps}$ to determine structural and transport properties of liquid $\mathrm{Al}_{1-\mathrm{x}} \mathrm{Cu}_{\mathrm{x}}$ alloys investigated $(x=10,30,40$ and 50 at $\% \mathrm{Cu})$. For structure analysis, 50 atomic configurations regularly spaced in time were selected and extracted from the MD trajectories and then were used for three-dimensional topological analysis including the Voronoi tessellation method [38]. Each atomic structure was brought to minimum energy using the steepest descent algorithm as implemented in LAMMPS.

Self-diffusion coefficient, describing the random walk motion of tagged atomic species $\beta$ ( $\beta=\mathrm{A}$, B for $A$ and $B$ being the particles of an AB binary system), was determined from the linear slope of the mean square displacement (MSD), equivalent to the GreenKubo formalism, given as:

$D_{\beta}=\lim _{t \rightarrow \infty} \frac{1}{N_{\beta}} \sum_{i=1}^{N_{\beta}} \frac{\left\langle\left|\mathbf{r}_{i, \beta}(t)-\mathbf{r}_{i, \beta}(t=0)\right|^{2}\right\rangle}{6 t}$,

where $r_{i, \beta}(t)$ is the position of particle $i$ of species $\beta$ at time $t$.

While for A-B binary systems various methods for computing the mutual diffusion coefficient exist, the first one is the simple Darken's relationship [39] linking the interdiffusion coefficient to self-diffusion coefficients, which is written as:

$D_{\mathrm{AB}}=C_{B} D_{A}+C_{A} D_{B}$.

In practice, Eq. (7) is not valid for concentrated melts with a strong associate forming tendency; hence, a modified Darken's formula is used instead. It incorporates an additional thermodynamic factor, $\Theta$ [39].

The second expression that can be used for mutual diffusion coefficient computation is the universal scaling law of Dzugutov [27] that is constituted by two important assumptions. The first includes the Enskog collision frequency describing binary collisions of dense hard-sphere fluids, only restricted to short-range repulsive forces, and governing the energy and momentum transfer [28]. In our investigations, we have considered the extended Enskog's theory on a binary liquid, where reduced self-diffusion coefficient written as $D^{*}{ }_{i}=D_{i} / \chi_{\mathrm{i}}$ is computed using relevant diffusion scale factor of $i$ th species in a binary liquid [40]:

$\chi_{1}=4 \sigma_{1}^{4} g_{11}\left(\sigma_{11}\right) \rho_{1} \sqrt{\frac{\pi k_{\mathrm{B}} T}{m_{1}}}+4 \sigma_{12}^{4} g_{12}\left(\sigma_{12}\right) \rho_{2} \sqrt{\frac{\pi k_{\mathrm{B}} T}{m_{1} m_{2}}}$.

Here, $g_{11}\left(\sigma_{11}\right), \rho_{1}$ and $m_{1}$ are partial pair-correlation functions of the hard sphere, atomic density and mass, respectively. An analogous factor is defined for second species by interchanging index 1 with 2 in Eq. (8). The second assumption relates to the 
frequency of the local structural relaxations associated with diffusive atomic motions dominated by cage effect which is proportional to the number of accessible configurations. In turn, the normalized diffusion $D^{*}$ is proportional to $\exp (S)$, where $S$ is the excess entropy expressed in $N k_{\mathrm{B}}$ units and $D^{*}$ can be estimated by reformulating Eq. (8) as:

$D^{*}=\left(\frac{D_{i}}{\chi_{i}}\right)^{X_{1}} \cdot\left(\frac{D_{j}}{\chi_{j}}\right)^{X_{j}}$.

If the $S_{\mathrm{cc}}(0)$ function is known, the interdiffusion coefficient of a binary liquid, $D_{\mathrm{AB}}$, can also be calculated using Eq. (10a):

$D_{\mathrm{AB}}=\frac{S_{\mathrm{CC}}(0)}{S_{\mathrm{CC}}(0, \mathrm{id})} \cdot D_{\mathrm{id}}$,

$S_{\mathrm{CC}}(0)=k \cdot T \cdot\left(\frac{\partial^{2} G_{\mathrm{mix}}}{\partial x^{2}}\right)^{-1}$.

$D_{i d}$ is the chemical diffusion coefficient for an ideal mixture. Importantly, Eq (10a) explores the structure-dynamics relation involving only macroscopic thermodynamic information and links the shortrange order to diffusion phenomenon [29]. $G_{\text {mix }}$ is sum of $G^{\text {id }}$ and $G^{x c}$, the latter is expressed in terms of thermodynamic parameters $\left(L_{i}^{L i q}, i=1,2,3\right)$ standing for Redlich-Kister polynomial coefficients [41].

The second important transport property, that is readily computed using molecular dynamics simulations, is shear viscosity $\eta$. It can be accessed through the Stokes-Einstein relation [42] [Eq. (11a)] or GreenKubo formalism [43] [Eq. (11b)], both of them describe the collective motion of a macroscopic particle and are formulated as:

$\eta_{\mathrm{SE}}=\frac{k_{\mathrm{B}} T}{6 \cdot \pi \cdot D_{\mathrm{AB}} \cdot R}$

$\eta_{\mathrm{GK}}=\frac{1}{k_{\mathrm{B}} \cdot T \cdot V} \int_{0}^{\infty}\left\langle\sigma^{x z}(t) \cdot \sigma^{x z}(0)\right\rangle \mathrm{d} t$.

Here $\sigma^{x z}$ is an off-diagonal element of the stress tensor computed by averaging over time, and similar averages are computed for the equivalent $y z$ and $x y$ components of the stress tensor. $R$ corresponds to the position of the first maximum of the radial distribution function.

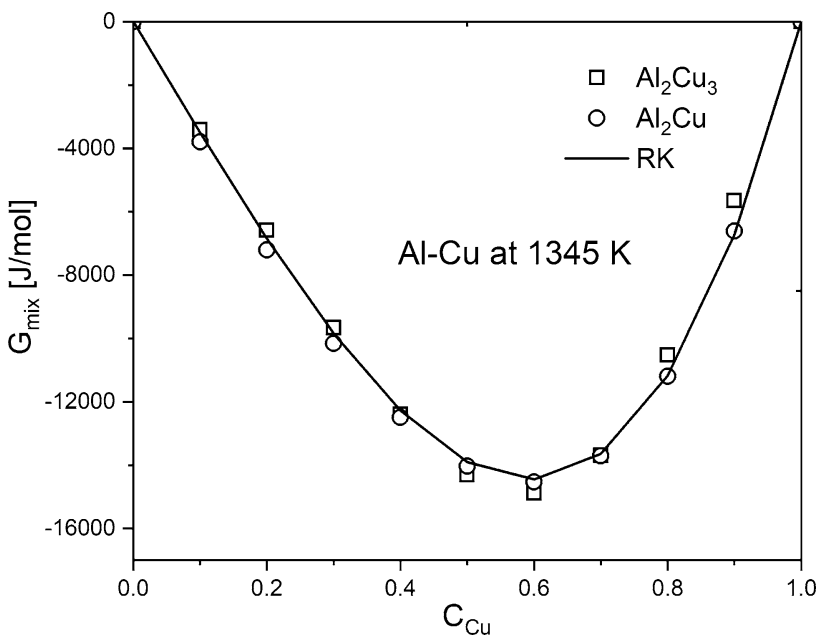

Figure 1 Computed integral Gibbs energy of mixing as a function of $\mathrm{Cu}$ concentration at $1345 \mathrm{~K}$ using $\mathrm{CFM}$ formalism with assumption of: circle $\mathrm{Al}_{2} \mathrm{Cu}$ and rectangle $\mathrm{Al}_{2} \mathrm{Cu}_{3}$ "associate" type, solid line- RK polynomial [44].

\section{Results and discussion}

\section{Thermodynamics-based modelling}

Keeping in mind the brief description of the CFM method, the mixing Gibbs free energies $\left(G_{\text {mix }}\right)$ were computed at $1345 \mathrm{~K}$ assuming the presence of two "associate" types, i.e. $\mathrm{Al}_{2} \mathrm{Cu}$ and $\mathrm{Al}_{2} \mathrm{Cu}_{3}$; the results are plotted in Fig. 1. The interaction energy parameters $W_{i j}$, used for fitting Gibbs free energy to the one computed employing the Redlich-Kister (RK) polynomial (solid line in Fig. 1), are given in Table 1 in the form of their temperature dependence for both associate types considered. Here, the RK's Gibbs energies are those computed using thermodynamic parameters $\left({ }^{i} L^{\mathrm{Liq}}, i=0,1,2,3\right)$ taken from Witusiewicz et al. [44] to Redlich-Kister polynomial [41] and they are collected in Table 1.

Two important features can be read from Fig. 1, with regard to the $G_{\text {mix }}$ minimum position and the convergence of the experimental points with those obtained from CFM computations. First of all, for both atomic cluster assumptions used for CFM, the $G_{\text {mix }}$ minimum position was located at the same $\mathrm{Cu}$ concentration (the $\mathrm{Al}_{40} \mathrm{Cu}_{60}$ alloy). Secondly, consideration of the $\mathrm{Al}_{2} \mathrm{Cu}$ atom cluster gives a slightly better agreement of CFM-based $G_{\text {mix }}$ with the RK's $G_{\text {mix }}$ as opposed to the second atomic cluster considered in this work. 
Table 1 Cluster types, interaction parameters $W, W_{A B}, W_{A A}$ and $W_{B B}$ used for CFM model and thermodynamic parameters of the Gibbs energy of Al-Cu liquid phase [44]

\begin{tabular}{|c|c|c|c|c|}
\hline Cluster & $W\left(\mathrm{~J} \mathrm{~mol}^{-1}\right)$ & $W_{\mathrm{AB}}\left(\mathrm{J} \mathrm{mol}^{-1}\right)$ & $W_{\mathrm{AA}}\left(\mathrm{J} \mathrm{mol}^{-1}\right)$ & $W_{\mathrm{BB}}\left(\mathrm{J} \mathrm{mol}^{-1}\right)$ \\
\hline $\mathrm{Al}_{2} \mathrm{Cu}$ & $\begin{array}{l}-39.2-0.0558 \times \mathrm{T} \\
+3 \mathrm{E}-5 \times \mathrm{T}^{2} \\
-6 \mathrm{E}-9 \times \mathrm{T}^{3}\end{array}$ & $\begin{array}{c}-5.92+0.011 \times \mathrm{T} \\
-6 \mathrm{E}-6 \times \mathrm{T}^{2} \\
+1 \mathrm{E}-9 \times \mathrm{T}^{3}\end{array}$ & 0 & $\begin{array}{l}-0.398-0.013 \times \mathrm{T} \\
+6 \mathrm{E}-6 \times \mathrm{T}^{2} \\
-2 \mathrm{E}-10 \times \mathrm{T}^{3}\end{array}$ \\
\hline $\mathrm{Al}_{2} \mathrm{Cu}_{3}$ & $\begin{array}{l}215.1-0.0506 \times \mathrm{T} \\
+4 \mathrm{E}-6 \times \mathrm{T}^{2} \\
-1 \mathrm{E}-10 \times \mathrm{T}^{3} \\
\text { Thermodynamic param } \\
\mathrm{Al}-\mathrm{Cu} \text { liquid phase } \\
{ }^{0} \mathrm{~L}^{\mathrm{Liq}}=-67,094+8.5 \\
{ }^{1} \mathrm{~L}^{\mathrm{Liq}}=32,148-7.11 \\
{ }^{2} \mathrm{~L}^{\mathrm{Liq}}=5915-5.8897 \\
{ }^{3} \mathrm{~L}^{\mathrm{Liq}}=-8175+6.04\end{array}$ & $\begin{array}{l}-570.2+0.120 \times \mathrm{T} \\
-8 \mathrm{E}-6 \times \mathrm{T}^{2} \\
+2 \mathrm{E}-10 \times \mathrm{T}^{3}\end{array}$ & $\begin{array}{l}-668.2+0.147 \times \mathrm{T} \\
-1 \mathrm{E}-5 \times \mathrm{T}^{2} \\
+3 \mathrm{E}-10 \times \mathrm{T}^{3}\end{array}$ & $\begin{array}{c}-3 \mathrm{E} 6+692.88 \times \mathrm{T} \\
-0.053 \times \mathrm{T}^{2} \\
+1 \mathrm{E}-6 \times \mathrm{T}^{3}\end{array}$ \\
\hline
\end{tabular}

\section{Diffusivity: CFM computation versus MD simulations}

Below, we report the self-diffusion (SD) coefficients of each species composing $\mathrm{Al}-\mathrm{Cu}$ alloys and the mutual diffusion coefficient. The temperature dependence of the SD coefficient for $\mathrm{Al}$ and $\mathrm{Cu}$ species is graphically presented in Fig. 2a, b, respectively. One can observe that the SD coefficients of both $\mathrm{Al}$ and $\mathrm{Cu}$ species exhibit significant deviation from a linear dependence for $\mathrm{Cu}$-deficient content of $\mathrm{Al}-\mathrm{Cu}$ alloys which becomes linear again for $\mathrm{Cu}-\mathrm{en}-$ riched alloys. An isotherm of $S D$ coefficients computed at $1345 \mathrm{~K}$ for $\mathrm{Al}$ and $\mathrm{Cu}$ atoms in liquid $\mathrm{Al}-\mathrm{Cu}$ alloys is plotted in Fig. 3, which includes also $S D$ coefficients taken from Meyer et al. measurements for $\mathrm{Al}$ [45] and $\mathrm{Cu}$ [46] and represented by diamonds. Therefore, a significant difference in the SD coefficient values between $\mathrm{Al}$ and $\mathrm{Cu}$ atomic species can be easily seen from Fig. 3 for the investigated $\mathrm{Al}-\mathrm{Cu}$ liquid alloys. Another striking feature is an appreciable decrease in SD coefficients between 10, 20 and 30 at $\% \mathrm{Cu}$ content as demonstrated in Fig. 2a, b. Such changes could be attributed to the variety of intermetallic phases present in solid $\mathrm{Cu}$-rich $\mathrm{Al}-\mathrm{Cu}$ alloys, in which the $\mathrm{Al}$ atoms are more likely to be chemically bonded to $\mathrm{Cu}$ atoms compared to the Al-rich alloys. Regarding the concentration-dependent SD coefficient of $\mathrm{Al}$, the present MEAM-MD simulations predict its almost linear decrease with increasing $\mathrm{Cu}$ content in liquid $\mathrm{Al}-\mathrm{Cu}$ alloys. A substantial disagreement is found between the present studies and the AIMD data of Wang et al. [16], which particularly concerns the $\mathrm{Al}_{80} \mathrm{Cu}_{20}$ alloy, and this issue has been previously discussed by Trybula [5]. Interestingly, SD coefficient of $\mathrm{Al}$ in liquid $\mathrm{Al}-\mathrm{Cu}$ alloys has attracted less scientific attention compared to that of copper, and this produces some difficulty in its discussion. In the case of SD coefficient of $\mathrm{Cu}$ species, investigated for selected binary Al-Cu alloys and drawn in Fig. 3, the MEAM-MD simulations also give its linear change and demonstrate a very good agreement with previous AIMD simulations performed for the liquid $\mathrm{Al}_{60} \mathrm{Cu}_{40}$ [18] and $\mathrm{Al}_{80} \mathrm{Cu}_{20}$ alloys [16]. Such observation does not apply to experimental data by Dahlborg et al. [21], whose values are substantially higher than both MEAM-MD and AIMD simulations results. To our best knowledge, no regular studies on diffusivity over a broad $\mathrm{Cu}$ concentration range using a single computational or experimental technique have been performed so far, which introduces a slight difficulty in their validation.

The mutual diffusion coefficient of $\mathrm{Al}-\mathrm{Cu}$ liquid alloys is drawn as a function of $\mathrm{Cu}$ concentration in Fig. 4. The linear change in observed composition dependence of self-diffusion coefficients is incompatible with that observed for the mutual one which is observed for the present MEAM-MD simulation results and CFM calculations, as it is illustrated in Fig. 4. Indeed, MEAM-MD and $\mathrm{CFM}-\mathrm{Al}_{2} \mathrm{Cu}$ calculations give results quite close to each other compared to an appreciable difference recorded for the CFM$\mathrm{Al}_{2} \mathrm{Cu}_{3}$ data. The most striking feature in $D_{\mathrm{AB}}$ coefficient behaviour is seen for Al-rich alloys: it consists in a nonlinear decrease of the $D_{\mathrm{AB}}$ coefficient with increasing $\mathrm{Cu}$ content which gradually changes over 


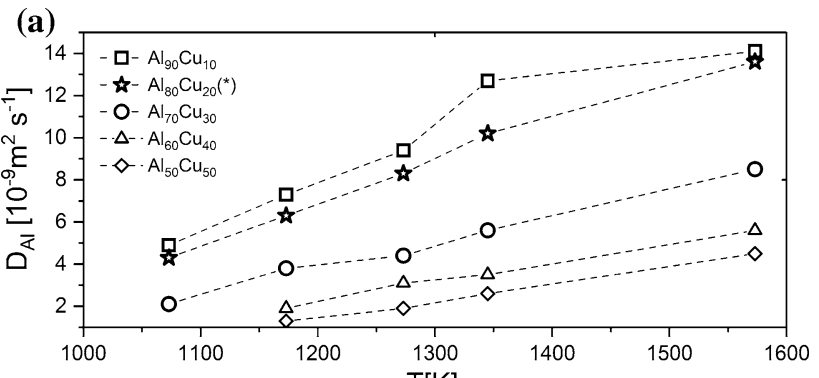

(b)

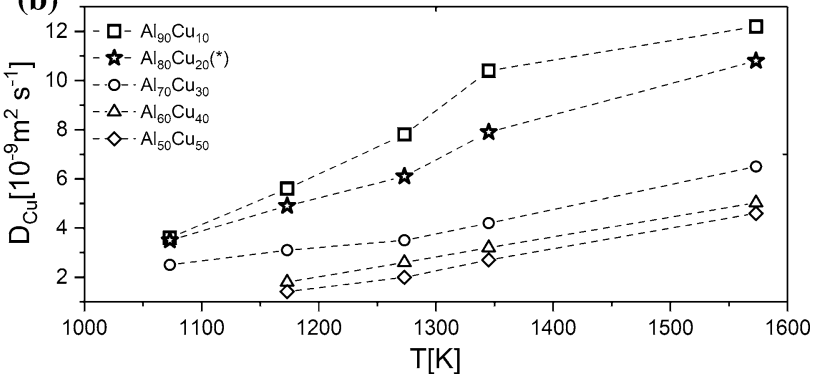

Figure 2 a, b Temperature-dependent self-diffusion coefficients of $\mathrm{Al}$ and $\mathrm{Cu}$ atomic species of liquid $\mathrm{Al}-\mathrm{Cu}$ alloys, respectively.

to a slight increase near the $\mathrm{Al}_{40} \mathrm{Cu}_{60}$ alloy composition. When CFM calculation results for $D_{\mathrm{AB}}$ coefficient are confronted with the ones computed using Eq. (10a), the CFM- $\mathrm{Al}_{2} \mathrm{Cu}$ results appear to correlate well with Eq. (10a) compared to MEAM-MD simulation data exhibiting a worse agreement. Apart from that, both "associate" assumptions employed in the CFM formalism, MEAM-MD simulation and Eq. (10a), are consistent in describing the negative

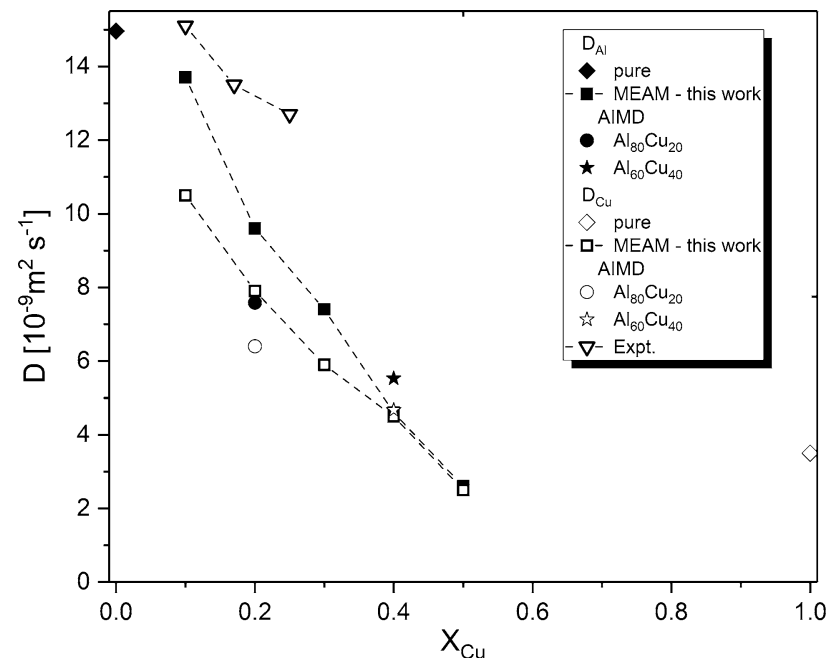

Figure $3 \mathrm{SD}$ coefficients isotherm as a function of $\mathrm{Cu}$ concentration computed at $1345 \mathrm{~K}$. AIMD data- $\mathrm{Al}_{80} \mathrm{Cu}_{20}$ [16] and $\mathrm{Al}_{60} \mathrm{Cu}_{40}$ [18], diamonds - expt. data for pure elements [45, 46], and asterisk - simulation data taken from [5]. deviation from linearity represented by a longdashed line in Fig. 4, corresponding to the chemical diffusion coefficient of ideal solution, $D_{\text {id }}$. The extended Darken's formulation has also been considered in our investigation for estimation of the $D_{\mathrm{AB}}$ coefficient. However, it gave significantly overestimated $D_{\mathrm{AB}}$ coefficients for $\mathrm{Al}-\mathrm{Cu}$ liquid alloy compositions in the vicinity of the intermetallic phases existing in solid state and consequently, they have not been depicted in Fig. 4. According to Trybula et al. studies [9], the assumption of $\mathrm{A}_{2} \mathrm{M}_{3}$ "associate" type enables one to predict a nonlinear change in mutual diffusion coefficient, even if various arbitrary parameters are used. Importantly, its curvature is synchronized with the shape of $S_{\mathrm{cc}}(0)$ function correlating with the thermodynamic driving force. As will be shown below, the two assumptions used in this work give two different descriptions of the fluctuation function for the liquid $\mathrm{Al}_{80} \mathrm{Cu}_{20}$ alloy. To prove the aforementioned statement, we need to have complete information derived from structural studies that will also be presented below.

Since a direct method for the determination of the concentration fluctuation function using molecular dynamics simulations has not been given yet, and its experimental determination is extremely difficult, first we try to discuss the data obtained using CFM formalism in our previous study [9], plotted in Fig. 5. Two different formalisms have been used for the thermodynamics-based computations, that is FVM

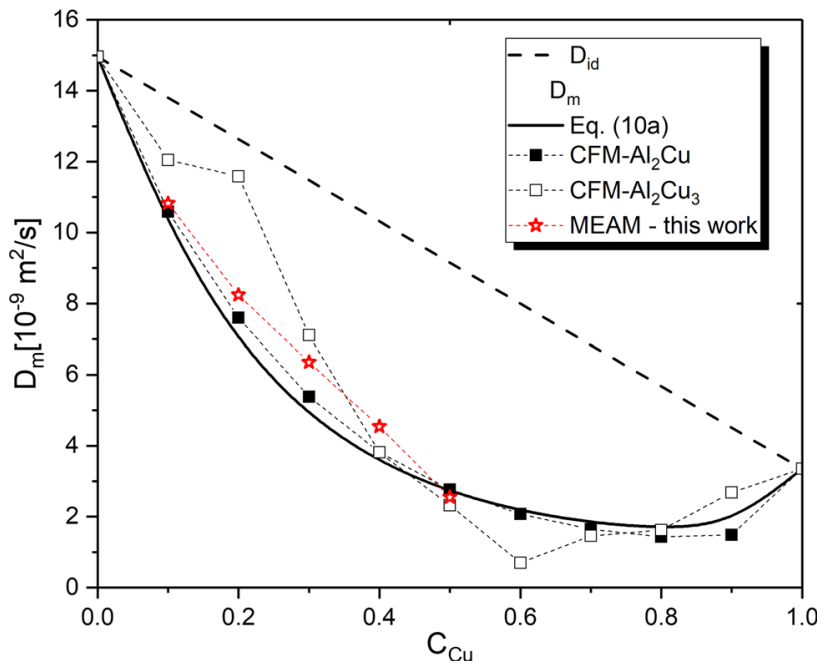

Figure 4 Mutual diffusion coefficient computed: squares-CFM formalism [Eq (7)], long-dashed line- $D_{\text {id }}$; solid line-Eq. (10a), and red stars-MEAM-MD simulations. Lines are guide to the eye. 


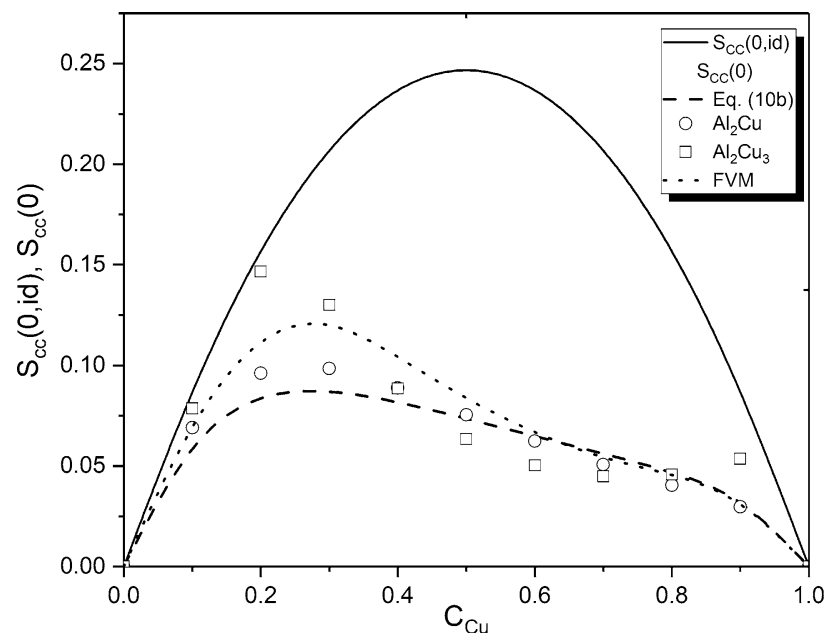

Figure 5 Concentration fluctuation function in the long-wave limit, $S_{\mathrm{cc}}(0)$ : solid line-ideal solution, dashed line-B-Th model [Eq. (10b)] [47], whereas symbols - modelled data at $1345 \mathrm{~K}$ : open triangles - CFM formalism, and stars-MEAM-MD data.

[4] and CFM (this work), which gave quite similar $S_{\mathrm{cc}}(0)$ function behaviour. In our present CFM computations, other atomic clusters have also been considered; however, we dismissed them from further discussion due to significant misfits in mixing thermodynamic properties giving an unrealistic description of concentration fluctuation and dynamic properties. Since the $\mathrm{Al}_{2} \mathrm{Cu}$ "associate" type is considered, a flat maximum located around 30 at $\%$ of $\mathrm{Cu}$ is observed along with almost perfect agreement to the approximated experimental $S_{\mathrm{CC}}(0)$ function (dashed line in Fig. 5). The latter has been assessed by using Eq. (10b) with $G_{\text {mix }}=\left(G^{x c}+G^{\text {id }}\right)$ calculated using the RK polynomial. At the same time, consideration of the $\mathrm{Al}_{2} \mathrm{Cu}_{3}$ cluster allows us to observe a sharp maximum at 20 at $\% \mathrm{Cu}$ content and a minimum spanned over $60-80$ at $\% \mathrm{Cu}$. Importantly, the CFM formalism with assumption of the $\mathrm{Al}_{2} \mathrm{Cu}_{3}$ "associate" predicts the $\mathrm{Al}_{90} \mathrm{Cu}_{10}$ and $\mathrm{Al}_{80} \mathrm{Cu}_{20}$ alloy to be ideal solutions, while both FVM and $\mathrm{CFM}-\mathrm{Al}_{2} \mathrm{Cu}$ computations as well as B-Th theory data contradict such behaviour. The latter have been computed as a second derivative of mixing Gibbs free energy with respect to concentration-Eq. (10b) [47]. Despite this fact, a substantial disagreement between FVM and $\mathrm{CFM}-\mathrm{Al}_{2} \mathrm{Cu}$ calculations is seen for $\mathrm{Al}$-rich $\mathrm{Al}-\mathrm{Cu}$ alloys when they are confronted with $\mathrm{B}-\mathrm{Th}$ results (dashed line in Fig. 5).

The $\mathrm{CFM}-\mathrm{Al}_{2} \mathrm{Cu}$ calculation gives a significantly smaller discrepancy from the approximated experimental data in comparison with the CFM- $\mathrm{Al}_{2}$ $\mathrm{Cu}_{3}$ results. Such a good correlation undoubtedly gives the first evidence of $\mathrm{Al}_{2} \mathrm{Cu}$ associate importance, and it might suggest their preponderance in liquid $\mathrm{Al}-\mathrm{Cu}$ alloys. Indeed, the trend observed in $S_{\mathrm{cc}}(0)$ change is compatible with the one that can be read from the phase diagram [11], namely intermetallic phase absence on the Al-rich side of the phase diagram corresponds to the appearance of $S_{\mathrm{cc}}(0)$ maximum in comparison with a smooth decrease observed for high-Cu-content $\mathrm{Al}-\mathrm{Cu}$ liquid alloys. The present MEAM-MD simulations give slightly higher values of the $S_{\mathrm{cc}}(0)$ function compared to the CFM- $\mathrm{Al}_{2} \mathrm{Cu}$ calculations and experimentally predicted data. However, they are still lower than line representing the ideal solution and, importantly, this does not change the structural description of liquid Al-Cu alloys. Because the $S_{\mathrm{cc}}(0)$ function values for $\mathrm{Al}-\mathrm{Cu}$ liquid alloys are lower than for ideal solution $\left(S_{\mathrm{cc}}(0) / S_{\mathrm{cc}}(0\right.$, id $\left.)<1\right)$, the $\mathrm{Al}-\mathrm{Cu}$ alloys rather have a tendency for compound formation according to the definition given by Bhatia and Thornton [47]. In turn, the present $\mathrm{CFM}-\mathrm{Al}_{2} \mathrm{Cu}$ and MEAM-MD simulation results are in line with this observation and FVM computation data [23] over the whole range of $\mathrm{Cu}$ concentrations investigated, as opposed to the selected ones found by our present CFM- $\mathrm{Al}_{2} \mathrm{Cu}_{3}$ calculation.

\section{Structure and local atomic arrangements: molecular dynamics study}

The structure factors $S(\mathrm{q})$ for a series of liquid $\mathrm{Al}-\mathrm{Cu}$ alloy compositions investigated in this work are plotted in Fig. 6 and confronted with X-ray experimental data measured by Brillo et al. [48] (black squares) and AIMD simulation results [16] (open circles). The $S(q)$ values for each of the studied $\mathrm{Al}-\mathrm{Cu}$ alloys exhibit a pronounced, narrow first peak becoming much more intense with increasing $\mathrm{Cu}$ content, while negligible differences in damped oscillations are seen for the second and third peaks. Such changes signify that $\mathrm{Al}-\mathrm{Cu}$ alloys become more densely packed liquids with increasing $\mathrm{Cu}$ content and inform about the loss of randomness in atomic packing of $\mathrm{Al}-\mathrm{Cu}$ alloys, that is also compatible with the observed decrease in $S_{\mathrm{cc}}(0)$ function and the analysis of the $\mathrm{Al}-\mathrm{Cu}$ phase diagram. Indeed, the existence of at least four different copper-rich intermetallic phases $\left(\theta-\mathrm{Al}_{2} \mathrm{Cu}, \eta\right.$-AlCu, $\gamma-\mathrm{Al}_{4} \mathrm{Cu}_{9}, \beta$-Bcc $)$ 


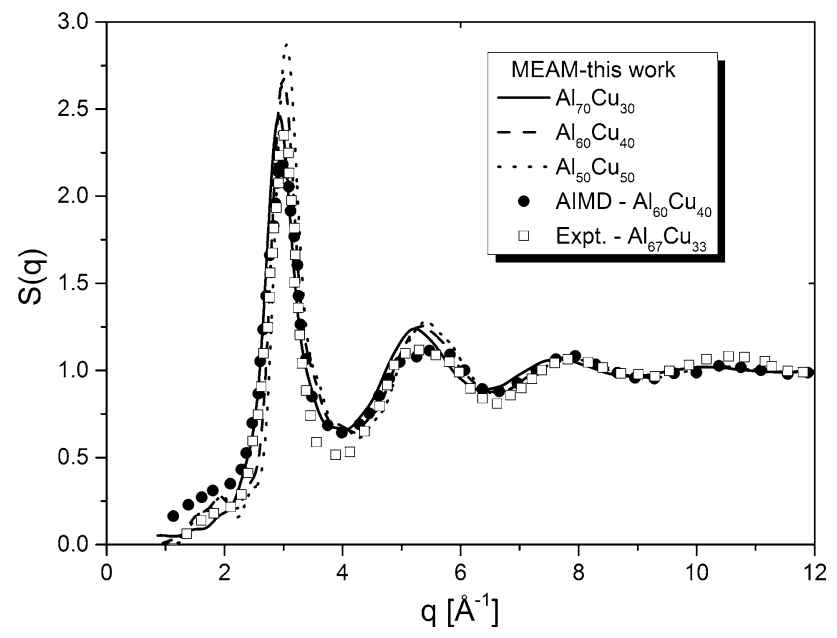

Figure 6 Structure factor of liquid $\mathrm{Al}_{1-\mathrm{x}} \mathrm{Cu}_{\mathrm{x}}$ alloys: solid, dashed and dotted lines represent MEAM data for $\mathrm{x}$ equal to 30, 40 and 50 at $\%$, respectively. Open circles and black squares-AIMD results for liquid $\mathrm{Al}_{60} \mathrm{Cu}_{40}$ [18] and X-ray experimental data for liquid $\mathrm{Al}_{67} \mathrm{Cu}_{33}$ alloy [35], respectively.

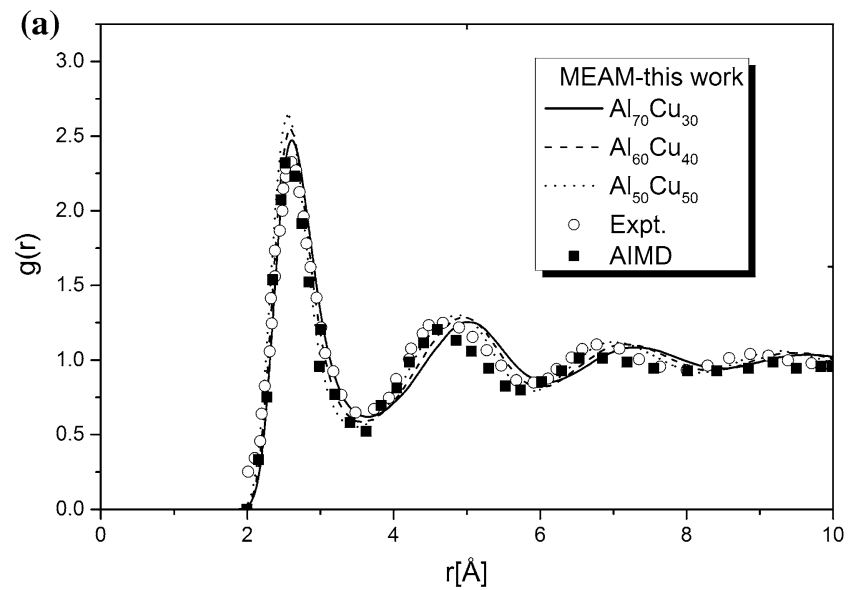

(c)

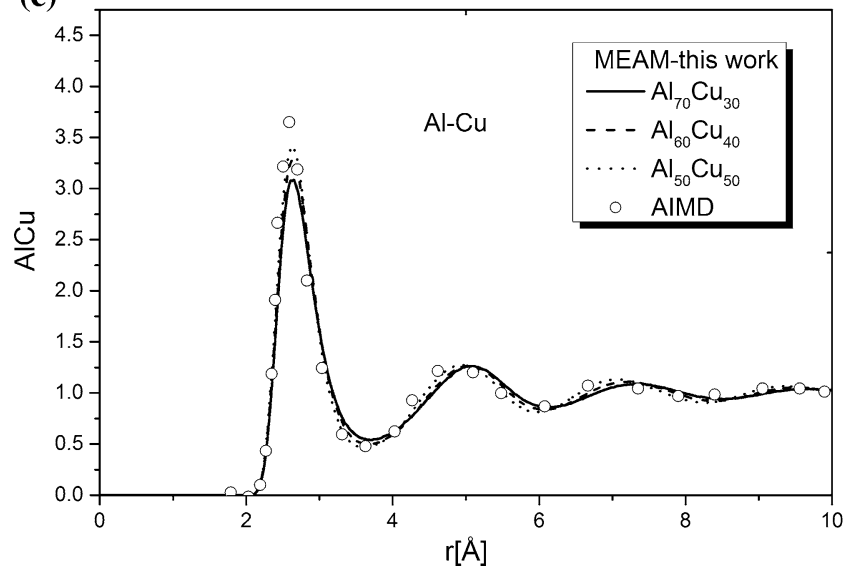

Figure 7 a Total and $\mathbf{b}-\mathbf{d}$ partial pair distribution functions for selected liquid $\mathrm{Al}-\mathrm{Cu}$ alloys. Solid, dashed and dotted lines-MD simulations for liquid $\mathrm{Al}_{70} \mathrm{Cu}_{30}, \mathrm{Al}_{60} \mathrm{Cu}_{40}$ and $\mathrm{Al}_{50} \mathrm{Cu}_{50}$,
[44] can imply on observing an increase in alloy ordering. The MEAM-MD simulations data are in acceptable agreement with available experimental results for the $\mathrm{Al}_{67} \mathrm{Cu}_{33}$ liquid alloy measured at $1023 \mathrm{~K}$ [35] and AIMD simulations performed for the $\mathrm{Al}_{60} \mathrm{Cu}_{40}$ liquid alloy at $1323 \mathrm{~K}$ [18], as position of the first peak is considered. A slightly different scenario can be perceived from the trend in intensity change of the first peak of $S(q)$ (Fig. 6). The MEAM-MD simulations show its increase with increasing $\mathrm{Cu}$ content, while AIMD simulations gave a less intense first peak compared to the experimental data.

Interestingly, MEAM-MD computations allow us to observe a weak pre-peak occurrence at short $q$ for liquid $\mathrm{Al}_{1-\mathrm{x}} \mathrm{Cu}_{\mathrm{x}}$ alloys for $x=0.3,0.4$ and 0.5 which can also be seen for X-ray and AIMD data in comparison with its absence in the $\mathrm{Al}_{80} \mathrm{Cu}_{20}$ liquid alloy [16]. Analogous observations emerge from the analysis of total pair-correlation function of liquid $\mathrm{Al}_{1-\mathrm{x}}$

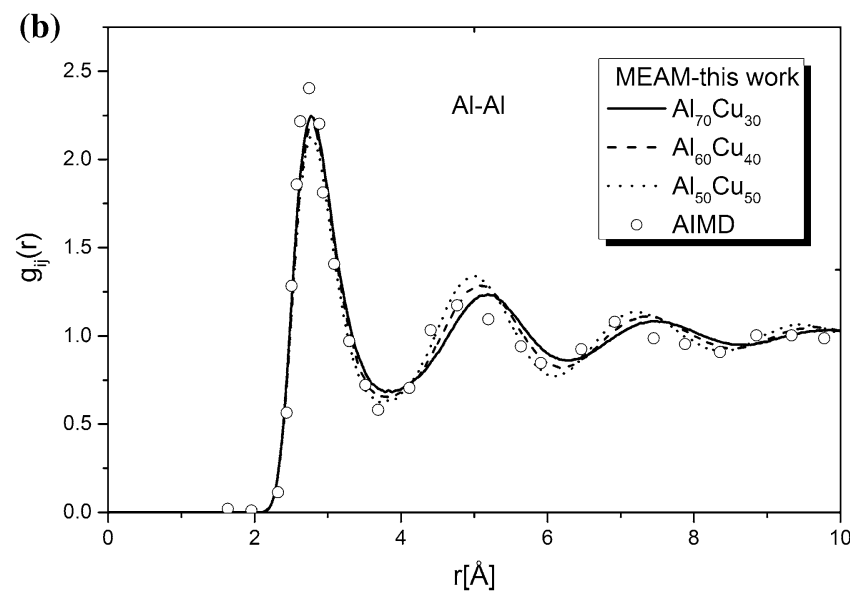

(d)

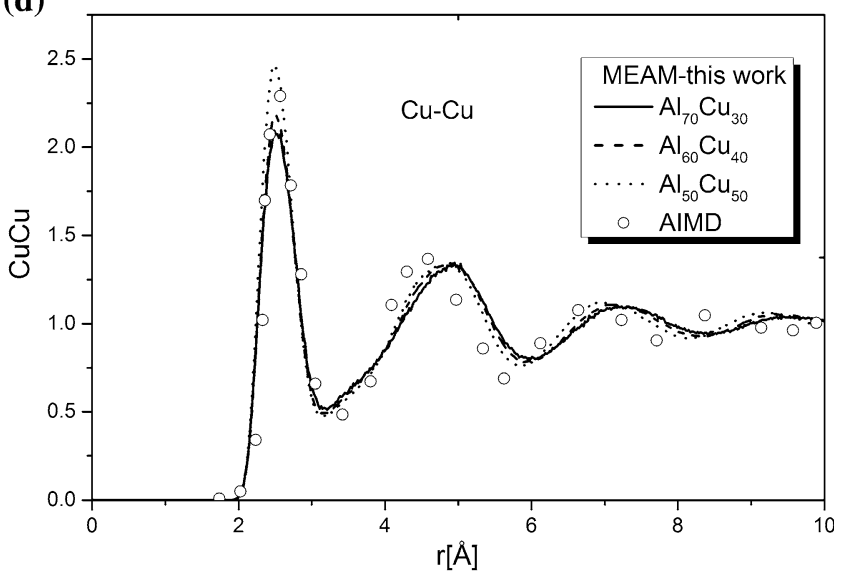

respectively; symbols (open circles)_-AIMD data [16] and (full squares)-experiment [35]. 
Table 2 Symbol, method and coordination number

\begin{tabular}{llllll}
\hline$Z$ & Method & \multicolumn{4}{l}{ Coordination number } \\
\cline { 3 - 6 } & & $\mathrm{Al}_{90} \mathrm{Cu}_{10}$ & $\mathrm{Al}_{70} \mathrm{Cu}_{30}$ & $\mathrm{Al}_{60} \mathrm{Cu}_{40}$ & $\mathrm{Al}_{50} \mathrm{Cu}_{50}$ \\
\hline$Z_{\mathrm{Al}}$ & $\mathrm{MEAM}$ & 11.74 & 12.68 & 13.32 & 13.47 \\
$Z_{\mathrm{Cu}}$ & & 10.99 & 10.95 & 11.17 & 10.97 \\
$Z_{\text {tot }}$ & & 11.06 & 11.47 & 12.03 & 12.22 \\
\hline
\end{tabular}

$\mathrm{Cu}_{\mathrm{x}}$ alloys for $x=0.3,0.4$ and 0.5 drawn in Fig. 7a. Some insignificant mismatch between present MEAM-MD results and available literature data is found, concerning the intensity of the first peak and shape of the second and higher-order peaks, whereas the position of the first peak is moving towards shorter interatomic distance with $\mathrm{Cu}$ content growth and approaching to that measured by Shtablavyi et al. [15] for pure $\mathrm{Cu}$ element. For clarity of Fig. 7a, MEAM and AIMD data for the liquid $\mathrm{Al}_{80} \mathrm{Cu}_{20}$ alloy are not appended; they are discussed in detail elsewhere [5].

Partial pair-correlation functions, contributing to the total correlation function, $g(r)$, that is $g_{\mathrm{AlAl}}(r)$, $g_{\mathrm{AlCu}}(r), g_{\mathrm{CuCu}}(r)$, are graphically presented in Fig. 7b-d, correspondingly. As it can be seen, MEAMMD data also show high consistency with X-ray diffraction [35] and AIMD simulations data [16, 49] with exception of the $g_{\mathrm{CuCu}}$ partial. According to our recent observation made for the $\mathrm{Al}_{80} \mathrm{Cu}_{20}$ liquid alloy [5], an adequate inconsistency in the position and shape of the high-order peaks in $g_{\mathrm{CuCu}}(r)$ partial has also been found. Therefore, it might mean that the atomic pair interactions described within MEAM method potential for $\mathrm{Cu}$ element need to be treated more attentively, which is beyond the scope of the present work. Apart from the slight inconsistency exhibited by the MEAM-MD data, any splitting of the second peak has not been seen for each of the $\mathrm{g}(r)$ partials. If it had been observed, such peculiarity would have been suggestive of the icosahedral shortrange ordering [16]. Interestingly, both experimental and AIMD data support the $S_{\mathrm{CC}}(0)$ function discussed above, which provides information that will be essential in further discussion concerning the topological local atom surrounding study.

By integration of each partial $g_{i j}(r)$ up to the first minimum, average partial and total coordination numbers $(\mathrm{CN})$ were computed; they are collected in
Table 3 Methods used and chemical short-range order parameter (CSRO)

\begin{tabular}{lllll}
\hline Method & \multicolumn{3}{l}{$\mathrm{CSRO}$} \\
\cline { 2 - 5 } & $\mathrm{Al}_{90} \mathrm{Cu}_{10}$ & $\mathrm{Al}_{70} \mathrm{Cu}_{30}$ & $\mathrm{Al}_{60} \mathrm{Cu}_{40}$ & $\mathrm{Al}_{50} \mathrm{Cu}_{50}$ \\
\hline MEAM-MD & -0.041 & -0.126 & -0.158 & -0.172 \\
CFM-Al ${ }_{2} \mathrm{Cu}$ & -0.031 & -0.102 & -0.145 & -0.188 \\
CFM-Al $\mathrm{Cu}_{3}$ & -0.015 & -0.148 & -0.193 & -0.231 \\
B-Th & -0.035 & -0.111 & -0.154 & -0.194 \\
\hline
\end{tabular}

Table 2. The average total $\mathrm{CN}$ for the investigated liquid $\mathrm{Al}-\mathrm{Cu}$ alloys increases with increasing $\mathrm{Cu}$ content, and importantly, and such trend is compatible to that displayed by AIMD simulations for $\mathrm{Al}_{80}$ $\mathrm{Cu}_{20}$ and $\mathrm{Al}_{60} \mathrm{Cu}_{40}$ liquid alloys [16, 18]; however, it is less pronounced. A significant rise in total coordination number obtained by performing MEAM-MD simulations can signify the occurrence of structural changes in atomic packing of liquid $\mathrm{Al}-\mathrm{Cu}$ alloys with $\mathrm{Cu}$ content growth. As it can also be seen, MEAM potential overestimates both experimental and AIMD data resulting from highly coordinated $\mathrm{Al}$ central atoms. It needs to be stressed that the MEAM potential usually gives higher coordination numbers with regard to experiment or AIMD data due to its sensitivity to the first minimum position of $g_{i j}(r)$ [5]. Importantly, recent experimental reports delivered a quite different look into the relationship between $\mathrm{CN}$ and $\mathrm{Cu}$ composition. The CNs increase substantially with increasing $\mathrm{Cu}$ content between 17 and $34 \%$ of $\mathrm{Cu}-\mathrm{Al}_{83} \mathrm{Cu}_{17}$ and $\mathrm{Al}_{66} \mathrm{Cu}_{34}$ alloys [35]. A similar relationship to that observed for our present MEAMMD simulations has found confirmation in a previous study of Al-Ni liquid alloys structure for which total and partial CNs increase with increasing $\mathrm{Ni}$ content [1]. Due to the similarity in thermodynamic and/or physicochemical properties' concentration and temperature dependences [50], similar trend in CNs change is also expected to be seen for the $\mathrm{Al}-\mathrm{Cu}$ liquid alloys.

Taking into account the information presented above, the atomic short-range order can be quantified by computing the Warren-Cowley parameter $(\alpha)$. Therefore, we compared all thermodynamics-based estimations-Eq. (5) and B-Th model [Eq. (10b)] with MEAM-MD simulations. For the latter case, we used random-packed model [51] defining the parameter $\alpha_{\text {tot }}$ as: 
$\alpha_{\mathrm{tot}}=\frac{c_{\mathrm{Cu}}\left(\mathrm{Z}_{\mathrm{Al}-\mathrm{Al}}-\mathrm{Z}_{\mathrm{Cu}-\mathrm{Al}}\right)+c_{\mathrm{Al}}\left(Z_{\mathrm{Cu}-\mathrm{Cu}}-Z_{\mathrm{Al}-\mathrm{Cu}}\right)}{Z_{\mathrm{tot}}}$.

The quantified chemical short-range order (CSRO) is gathered in Table 3 for MEAM-MD simulations data, CFM computations and available literature data [30] computed at $1345 \mathrm{~K}$.

CFM computations performed assuming $\mathrm{Al}_{2} \mathrm{Cu}$ and $\mathrm{Al}_{2} \mathrm{Cu}_{3}$ give negative $\mathrm{CSRO}$ parameter, and therefore, its sign confirms the presence of chemical ordering in the liquid $\mathrm{Al}-\mathrm{Cu}$ alloys which does increase with growing $\mathrm{Cu}$ content. As it can be seen, $\mathrm{CFM}-\mathrm{Al}_{2} \mathrm{Cu}$ calculations predict slightly higher CSRO parameter compared to the one estimated using Eq. (10b) and experimental thermodynamic data [30]. For further comparison, a recent study of Das et al. [52]. provided some interesting observations related to chemical description of liquid $\mathrm{Al}-\mathrm{Ni}$ alloys, involving diffusion and CSRO. Basically, the nonlinear compositional dependence of diffusion coefficients corresponds to increasing CSRO, moving towards the Ni-rich side. Note that a similar relationship is exhibited by the analysed liquid $\mathrm{Al}-\mathrm{Cu}$ alloys, namely the growth in CSRO with increasing $\mathrm{Cu}$ content reflects in decreasing self- and mutual diffusion coefficients. By definition, the CSRO parameter describes chemical local atom environment; therefore, its increase informs that liquid structure becomes densely packed reflecting in a significant deviation from random atom ordering. Such behaviour is a good example of the hardsphere-like liquids behaviour, for which mass transport is strongly correlated with packing fraction of atoms [53, 54]. To have a complete view onto the mass transport property, we decide to extend our consideration on viscosity investigation, which will be discussed in the following section.

Three-dimensional analysis based on the Voronoi tessellation was performed, in which a geometrical construction divides the investigated space into polyhedra, containing a single atom, called Voronoi cells (VC). The local atom topology as a function of composition and temperature is inspected. Within Voronoi analysis, the total number of the VC faces corresponds to the coordination number assigned to the central atom. Voronoi index $n_{3}, n_{4} \cdot n_{5}, n_{6}, \ldots$ is used to differentiate between the VC types, where $n_{i}$ is the number of $i$-edged sides in the polyhedron. This structural tool allows to distinguish body- and face-centred cubic (b.c.c. and f.c.c.), as well as hexagonal close-packed (h.c.p.) structures. Further details on the Voronoi tessellation method, they can be found elsewhere $[55,56]$. Ten types of Voronoi cells (VC) are found to be in reasonable abundance among the 100 different types of cells around $\mathrm{Al}$ and $\mathrm{Cu}$ atomic species in liquid $\mathrm{Al}_{1-\mathrm{x}} \mathrm{Cux}(x=10,30,40$ and 50) alloys at $1345 \mathrm{~K}$. VCs abundance and their geometrical construction are drawn in Fig. 8.

High coordination numbers around $\mathrm{Al}$ and $\mathrm{Cu}$ species correspond to high-indexed Voronoi cells (VCs). As compared to the AIMD data at $1345 \mathrm{~K}$ for the $\mathrm{Al}_{60} \mathrm{Cu}_{40}$ liquid alloy [49], some similarities have been found concerning abundance and cluster types distinguished in the $\mathrm{Al}-\mathrm{Cu}$ liquid alloys examined. At first, icosahedral clusters of $<00120>$ indexideal icosahedron are found to be not the most abundant index compared to distorted icosahedra of $\left\{<\begin{array}{llll}0 & 1 & 10 & 2\end{array},<,<0364>\right\}$. It is argued that local icosahedral structures have a positive influence on stabilization of undercooled liquid state [57] resulting from their compact structure; therefore, we can expect that this issue is also applied to liquid $\mathrm{Al}-\mathrm{Cu}$ alloys. On the other hand, their preponderant abundance has a beneficiary influence on slowing down relaxation processes distinguished during glass transition. Compact structures, like icosahedra derivatives, can be responsible for slow structural dynamics compared to loosely packed clusters undergoing fast structural dynamics $[58,59]$ resulting in significantly displacing local atom regions. Recognizable discrimination in VCs as it has been found between $\mathrm{Al}$ and $\mathrm{Cu}$ local surrounding could have indicated that liquid $\mathrm{Al}-\mathrm{Cu}$ alloys undergo two relaxation processes. Invoking at this moment the previously discussed functions, representing chemistry of local atom surrounding: structure factor and distribution function, any evidence of middle-range ordered clusters has not been found. Therefore, it can be stated that $\mathrm{Al}-\mathrm{Cu}$ liquid alloys undergo processes which enable liquid materials to crystallize rather than have an amorphous structure, excepting only the Al-rich alloys, due to the existence of a number of interatomic phases stabilizing the solid state of the $\mathrm{Al}-\mathrm{Cu}$ system [11]. Quite interestingly, such a conclusion was confirmed by Wang et al. [16]; in particular, the liquid $\mathrm{Al}_{80} \mathrm{Cu}_{20}$ alloy can be classified as a strong liquid according to Angel classification [60] with fragility value lower than 10 that provides a 


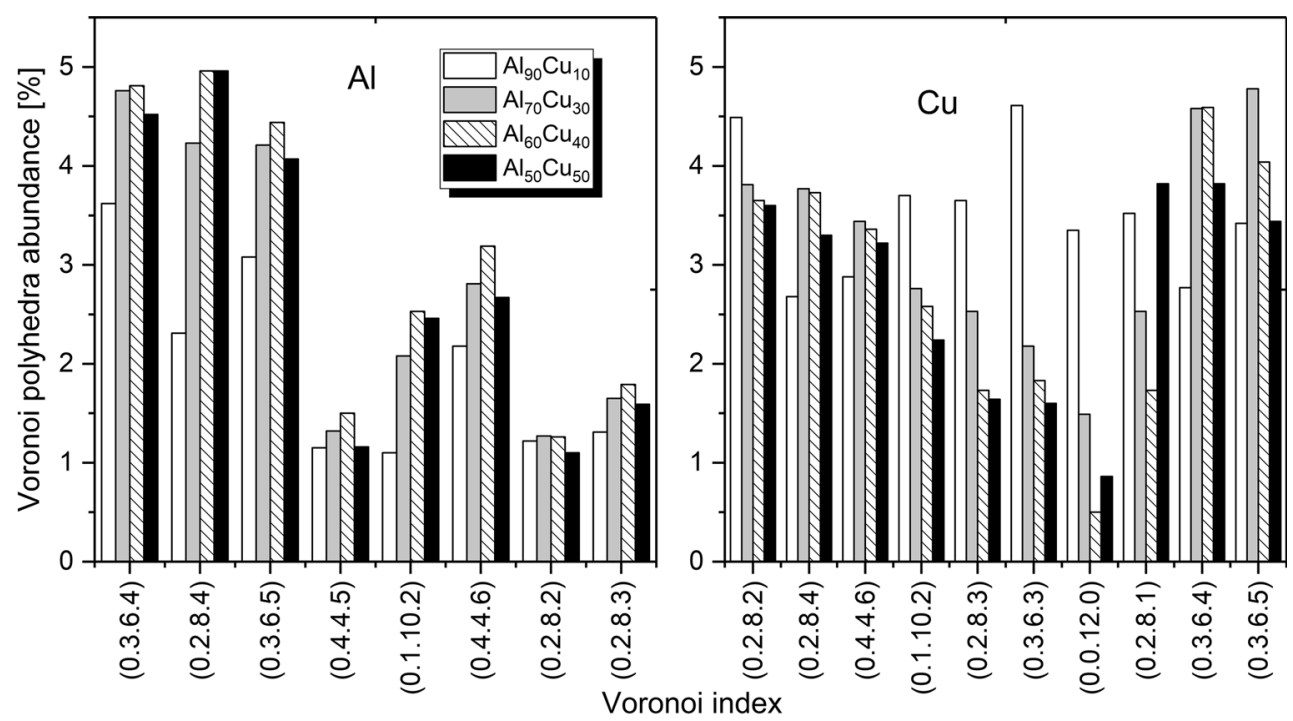

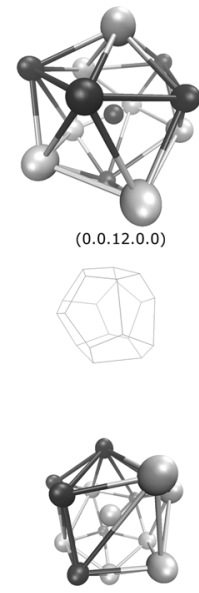

(0.1.10.2.0)
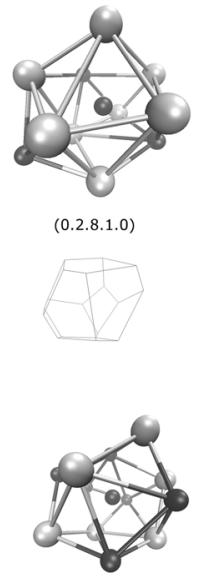

(0.3.6.3.0)

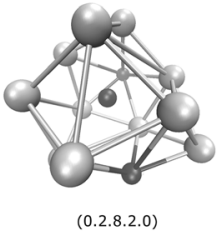

$(0.2 \cdot 8.2 .0)$
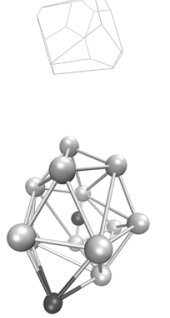

(0.3.6.4.0)

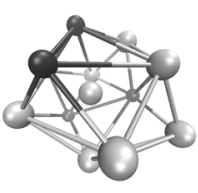

$(0.2 .8 .3 .0)$
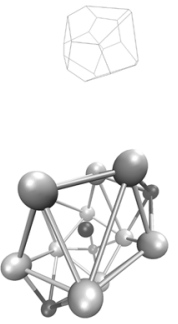

(0.3.6.5.0)

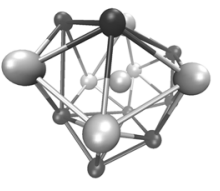

$(0.2 .8 .4 .0)$

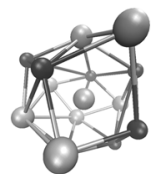

(0.4.4.6.0)

Figure 8 The abundance of Voronoi cells (top) found at $1345 \mathrm{~K}$ around $\mathrm{Al}$ and $\mathrm{Cu}$ species in liquid $\mathrm{Al}-\mathrm{Cu}$ alloys and their geometrical construction (bottom).

straightforward suggestion of weak glass forming ability.

\section{Viscosity}

For viscosity determination, at first, we confine our investigation to test the validity of Stokes-Einstein (S-E) [42] relation for Al-Cu liquid alloys using only MEAM-MD data. Its compositional dependence is shown in Fig. 9. As compared to the experimental data collected by Brillo [48], the inability of S-E relation to accurately reproduce the experimental data (red stars) can be easily seen which corresponds to a substantial underestimation of experiment. Such behaviour eliminates the S-E equation consideration from further studies of liquid Al-Cu alloys in contrast to the simple liquids, for which this relation is obeyed. Consequently, we employ the Green-Kubo (G-K) formalism [43] [Eq. (11b)] as previously Asta et al. [61] used for liquid $\mathrm{Al}-\mathrm{Ni}$ alloys investigation. Importantly, the G-K approach (circles) allows to get an overall $5-15 \%$ agreement with the experiment over a broad $\mathrm{Cu}$ concentration range. 


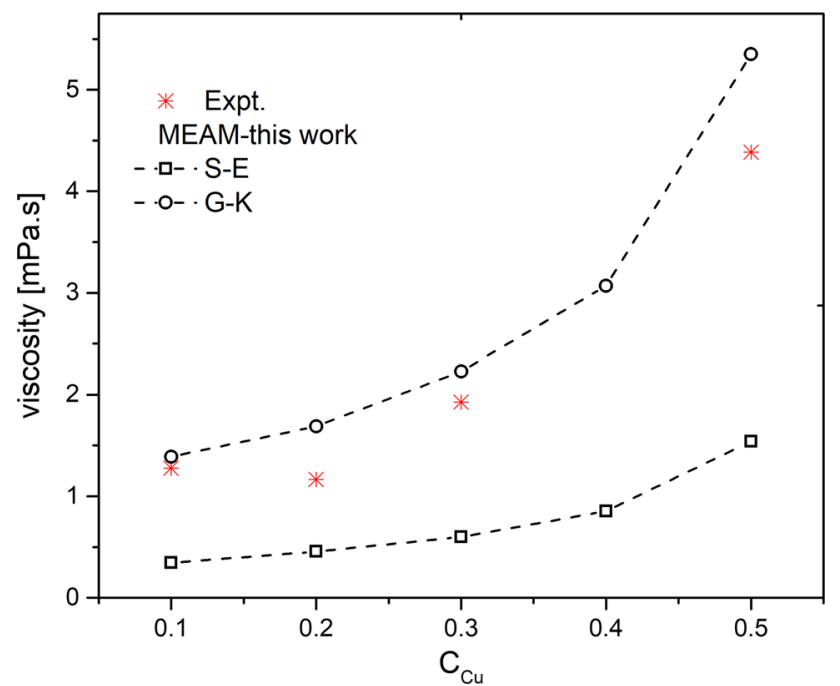

Figure 9 MEAM MD computed (full and empty squares) and measured (stars) viscosity at $1345 \mathrm{~K}$ as a function of $\mathrm{Cu}$ concentration. Experimental data were taken from Brillo et al. [48]. Lines are guide to the eye.

The nonlinear behaviour of viscosity is strongly correlated with nonlinear diffusion coefficients change as a result of the CSRO degree increasing with $\mathrm{Cu}$ content growth. Quite interestingly, the experiment also exhibits the same behaviour [21], compared to an almost complete failure given by the S-E relation. On the Al-rich side, where no intermetallic phases exist, viscosity slightly decreases towards the $\mathrm{Al}_{80} \mathrm{Cu}_{20}$ alloy and suddenly increases as the $\mathrm{Al}_{2} \mathrm{Cu}$ compound starts to form [11]. In turn, an estimation of the fragility parameter $[60,62,63]$ is not necessary

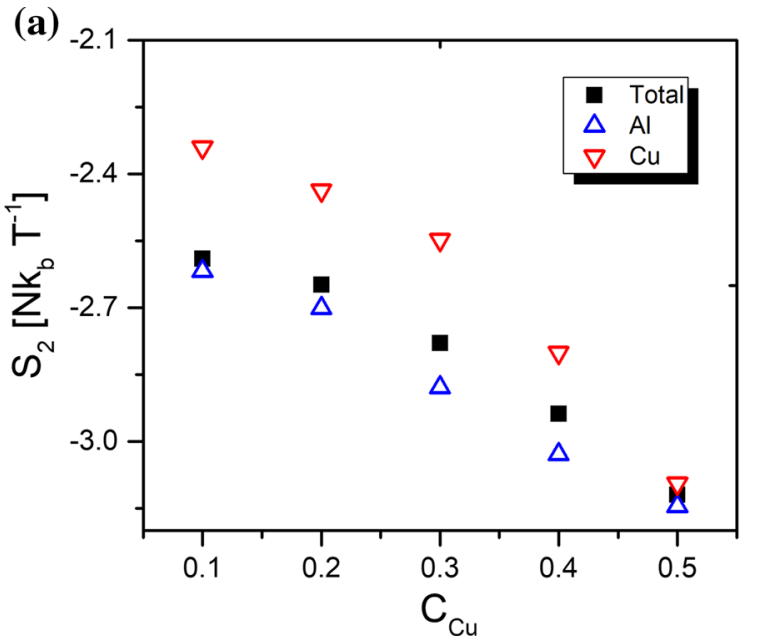

due to a negligible evidence of icosahedral motifs or Wang et al. remarks [16] as well as significant $\mathrm{Al}_{2} \mathrm{Cu}$ compound influence stimulating the solidification of liquid Al-Cu alloys [14, 64-66].

\section{Excess entropy}

To define the structure-dynamics relationship in liquid $\mathrm{Al}-\mathrm{Cu}$ alloys, we considered the universal scaling law relating diffusion coefficient to compute the excess entropy as formulated in the original work by Dzugutov [27]. In the frame of this formulation, the excess entropy (expressed in $k_{B}$ units) is restricted to a two-body contribution:

$S_{2}=-2 \pi \rho \int_{0}^{\infty}\{g(r) \ln [g(r)]-[g(r)-1]\} r^{2} d r$,

for $\rho$ being the number density. In other words, Dzugutov scaling law is an important contribution combining the kinetics of a liquid to a static thermodynamic quantity, $S$. In our case, it is $S_{2}$ function coupled to an accessible structural property of a liquid-partial pair-correlation function, whereas the total excess entropy is given by $S_{2}=X_{\mathrm{Al}^{-}}$ $S_{2}^{\mathrm{Al}}+\mathrm{X}_{\mathrm{Cu}} S_{2}^{\mathrm{Cu}}$, where $S_{2}^{\mathrm{Al}}$ and $S_{2}^{\mathrm{Cu}}$ are partial molar entropy of $\mathrm{Al}$ and $\mathrm{Cu}$ atoms, respectively. The partial and total $S_{2}$ function computed at $1345 \mathrm{~K}$ are plotted in Fig. 10a.

For the investigated $\mathrm{Al}-\mathrm{Cu}$ alloys, we observe a decrease in total excess entropy $\left(S_{2}\right)$ with increasing $\mathrm{Cu}$ content as well as substantial discrimination in

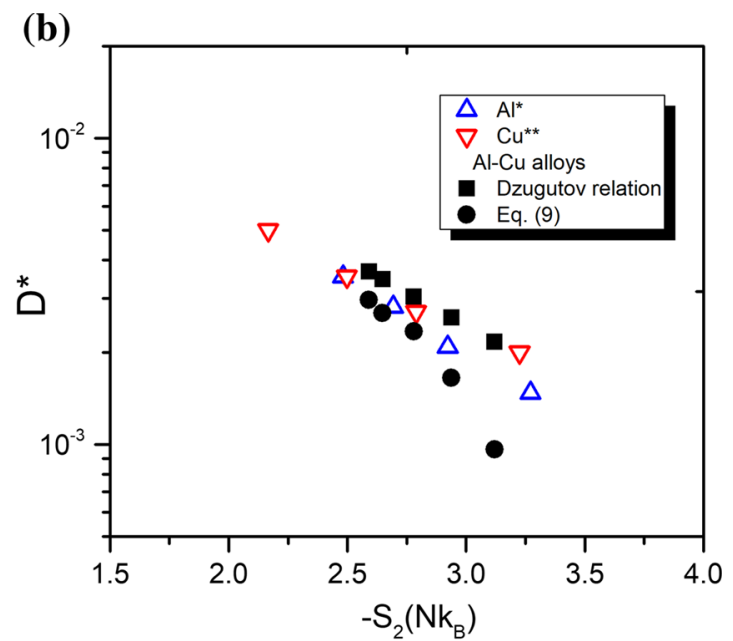

Figure 10 a Computed total and partial entropies $\left(S_{2}\right)$ as a function of $\mathrm{Cu}$ composition at $1345 \mathrm{~K}$ and $\mathbf{b}$ scaled diffusion versus entropy for liquid $\mathrm{Al}-\mathrm{Cu}$ alloys and pure elements: $\mathrm{Al}[27]$ and $\mathrm{Cu}[61]$. 
partial entropy between $\mathrm{Al}$ and $\mathrm{Cu}$ elements on the Al-rich side which decreases with increasing $\mathrm{Cu}$ content. Displayed compositional dependences of $S_{2}$ and partial entropies correlate with the chemical short-range order (CSRO) changes discussed before. Basically, low CSRO degree on the Al-rich side corresponds to a low negative $S_{2}$ value compared to middle $\mathrm{Cu}$ composition for which significant degree of CSRO and abundance of icosahedral motifs have been recorded. This is a good demonstration of $S_{2}$ function ability to appropriately reflect the local atom arrangements within the nearest neighbour environment, which can be characterized by CSRO or ISRO (icosahedral short-range ordering), in spite of negligence of many-body correlations. Similarly to the impact of CSRO and ISRO on the $S_{2}$ function compositional behaviour of $\mathrm{Al}-\mathrm{Cu}$ liquid alloys, we also notice such confirmation for self-diffusion coefficients' changes. The decrease in both SD coefficients corresponds to respective decreases in $S_{2}^{\mathrm{Al}}$ and $S_{2}^{\mathrm{Cu}}$ entropies. In relation to this, the significant differentiation in SD values and average coordination number between $\mathrm{Al}$ and $\mathrm{Cu}$ species has a big influence on the trend in excess and partial entropies.

To clarify the effect of diffusion on excess entropy, we inspect the scaled diffusion coefficient $\left(D^{*}\right)$ using Enskog theory which is presented in Fig. $10 \mathrm{~b}$ as a function of excess entropy $S_{2}$ at $1345 \mathrm{~K}$. It has been computed for the all Al-Cu alloys investigated and confronted with the literature data for pure liquid $\mathrm{Al}$ [27] and $\mathrm{Cu}$ [61] metals. Normalized diffusion $D^{*}$ computed, using Eq. (9), scales adequately to those displayed by pure liquid $\mathrm{Al}$ and $\mathrm{Cu}$ atoms, excepting only the liquid binary $\mathrm{Al}_{50} \mathrm{Cu}_{50}$ system exhibiting a significant coefficient shift. As it can be seen, $D^{*}$ decreases with increasing $\left(-S_{2}\right)$ function and its decrease is compatible with that exhibited in Fig. 10a.

\section{Conclusions}

In conclusion, the structure and chemistry of liquid $\mathrm{Al}-\mathrm{Cu}$ alloys have been studied by means of molecular dynamics, using modified embedded atom model potential and CALPHAD-type modelling based on a quasi-chemical approximation for weakly compound-forming melts (CFM formalism).

The CFM computations provided important knowledge on the interplay between thermodynamics, kinetics and structure over a broad $\mathrm{Cu}$ concentration range which allowed to supplement the database of $\mathrm{Al}-\mathrm{Cu}$ liquid alloy properties. The assumption of $\mathrm{Al}_{2}$ $\mathrm{Cu}$ compound dominance within the CFM formalism allowed to accurately reproduce the available experimental data, and consequently explain the experimental structural characterization of two liquid $\mathrm{Al}-\mathrm{Cu}$ alloys performed by Brillo et al. [35].

Compositional dependence of concentration fluctuation function, $S_{\mathrm{cc}}(0)$, displayed significant deviation from regular solution comparable with predictions of the CFM formalism and experimental data. In turn, the nonlinear change of diffusion coefficients (both self and mutual) and viscosity is associated with pronounced chemical short-range ordering (CSRO) increasing with $\mathrm{Cu}$ growth confirmed by present molecular dynamics simulations. A significant effect of increasing dense-packing liquid $\mathrm{Al}-\mathrm{Cu}$ alloys on excess entropy corresponding to an appreciable decrease in partial and total entropies has been found.

To summarize, using the hybrid approach presented herein, we gave a compact and detailed description of the structure, thermodynamics and kinetics of liquid phase, valuable for manufacturing of solid materials based on Al-Cu alloys. The studies presented in this work are the first ones concerning the $\mathrm{Al}-\mathrm{Cu}$ alloys and the used methodology, which allowed us to find another hard-sphere-like metallic system whose transport properties are strongly affected by packing effects. Thermodynamics-based modelling allowed to quickly cover a broad concentration range compared to molecular dynamics simulations employing semi-empirical interatomic forces fitted to ab initio calculation results. Although the former calculations do not explicitly consider the atomic level, they need to be supported by atomistic computations to gain deeper insight into the physical phenomenology of any studied melt.

\section{Acknowledgements}

One of the author (M.E.T) would like to acknowledge the financial support from National Science Centre, Poland (Preludium Grant No: ST8/2012/0485) and continued support from the Carl Tryggers Stiftelse for Vetenskaplig Forskning for carrying out the research studies at KTH Royal Institute of Technology (Project No. 16:253). The computations were performed on resources provided by Academic 
Computer Centre CYFRONET AGH using PLGRID Infrastructure.

\section{Author contributions}

M.E.T. had the idea for this work and performed all the atomistic simulations and thermodynamics-based modelling, as well as wrote the manuscript. P.W.S. performed Voronoi polyhedral analysis and the geometrical construction of each Voronoi cell, as well as corrected the manuscript. P.A.K. reviewed and corrected the manuscript.

\section{Open Access}

This article is distributed under the terms of the Creative Commons Attribution 4.0 International License (http://creativecommons.org/licenses/by/ $4.0 /$ ), which permits unrestricted use, distribution, and reproduction in any medium, provided you give appropriate credit to the original author(s) and the source, provide a link to the Creative Commons license, and indicate if changes were made.

\section{References}

[1] Asta M, Morgan D, Hoyt JJ et al (1999) Embedded-atommethod study of structural, thermodynamic, and atomictransport properties of liquid $\mathrm{Ni}-\mathrm{Al}$ alloys. Phys Rev B 59:14271-14281. https://doi.org/10.1103/PhysRevB.59. 14271

[2] Horbach J, Das SK, Griesche A et al (2007) Self-diffusion and interdiffusion in $\mathrm{Al} 80 \mathrm{Ni} 20$ melts: simulation and experiment. Phys Rev B 75:174304. https://doi.org/10.1103/ PhysRevB.75.174304

[3] Das SK, Horbach J, Koza MM et al (2005) Influence of chemical short-range order on atomic diffusion in $\mathrm{Al}-\mathrm{Ni}$ melts. Appl Phys Lett 86:2003-2006. https://doi.org/10. $1063 / 1.1845590$

[4] Trybula M, Jakse N, Gasior W, Pasturel A (2014) Structural and physicochemical properties of liquid $\mathrm{Al}-\mathrm{Zn}$ alloys: a combined study based on molecular dynamics simulations and the quasi-lattice theory. J Chem Phys 141:1-9. https:// doi.org/10.1063/1.4903209

[5] Trybula ME (2016) Structure and transport properties of the liquid A180Cu20 alloy-a molecular dynamics study. Comput Mater Sci 122:341-352. https://doi.org/10.1016/j. commatsci.2016.05.029
[6] Hoyt JJ, Asta M (2002) Atomistic computation of liquid diffusivity, solid-liquid interfacial free energy, and kinetic coefficient in Au and Ag. Phys Rev B 65:214106. https://doi. org/10.1103/PhysRevB.65.214106

[7] Bhatia AB, Singh RN (1984) A quasi-lattice theory for compound forming molten alloys. Phys Chem Liq 13:177-190. https://doi.org/10.1080/00319108408080778

[8] Singh RN (1987) Short-range order and concentration fluctuations in binary molten alloys. Can J Phys 65:309-325. https://doi.org/10.1139/p87-038

[9] Trybula M, Gancarz T, Gasior W, Pasturel A (2014) Bulk and surface properties of liquid $\mathrm{Al}-\mathrm{Li}$ and $\mathrm{Li}-\mathrm{Zn}$ alloys. Metall Mater Trans A 45:5517-5530. https://doi.org/10. 1007/s11661-014-2524-6

[10] Novakovic R, Muolo ML, Passerone A (2004) Bulk and surface properties of liquid $\mathrm{X}-\mathrm{Zr}(\mathrm{X}=\mathrm{Ag}, \mathrm{Cu})$ compound forming alloys. Surf Sci 549:281-293. https://doi.org/10. 1016/j.susc.2003.12.006

[11] Murray JL (1985) The aluminium-copper system. Int Met Rev 30:211-234. https://doi.org/10.1179/imtr.1985.30.1.211

[12] Wolverton C, Ozolins V (2001) Entropically favored ordering: the metallurgy of $\mathrm{Al}_{2} \mathrm{Cu}$ revisited. Phys $\mathrm{Rev}$ Lett 86:5518-5521. https://doi.org/10.1103/PhysRevLett.86. 5518

[13] Hu S, Baskes M, Stan M, Chen L (2006) Atomistic calculations of interfacial energies, nucleus shape and size of $\theta^{\prime}$ precipitates in $\mathrm{Al}-\mathrm{Cu}$ alloys. Acta Mater 54:4699-4707. https://doi.org/10.1016/j.actamat.2006.06.010

[14] Boyd JD, Nicholson RB (1971) The coarsening behaviour of $\theta^{\prime \prime}$ and $\theta^{\prime}$ precipitates in two $\mathrm{Al}-\mathrm{Cu}$ alloys. Acta Metall 19:1379-1391. https://doi.org/10.1016/0001-6160(71) 90076-9

[15] Shtablavyi I, Mudry S, Mykhaylyuk V, Rybicki J (2008) The structure of $\mathrm{Al}-\mathrm{Cu}$ and $\mathrm{Al}-\mathrm{Si}$ eutectic melts. J Non Cryst Solids 354:4469-4474. https://doi.org/10.1016/j.jnoncrysol. 2008.06.071

[16] Wang WY, Han JJ, Fang HZ et al (2015) Anomalous structural dynamics in liquid $\mathrm{Al} 80 \mathrm{Cu} 20$ : an ab initio molecular dynamics study. Acta Mater 97:75-85. https://doi. org/10.1016/j.actamat.2015.07.001

[17] Lee B-JBBJ, Baskes MI (2000) Second nearest-neighbor modified embedded-atom-method potential. Phys Rev B 62:8564-8567. https://doi.org/10.1103/PhysRevB.62.8564

[18] Wang SY, Kramer MJ, Xu M et al (2009) Experimental and $\mathrm{ab}$ initio molecular dynamics simulation studies of liquid Al $60 \mathrm{Cu} 40$ alloy. Phys Rev B 79:144205. https://doi.org/10. 1103/PhysRevB.79.144205

[19] Dziedzic J, Winczewski S, Rybicki J (2016) Structure and properties of liquid $\mathrm{Al}-\mathrm{Cu}$ alloys: empirical potentials 
compared. Comput Mater Sci 114:219-232. https://doi.org/ 10.1016/j.commatsci.2015.12.014

[20] Schick M, Brillo J, Egry I, Hallstedt B (2012) Viscosity of $\mathrm{Al}-\mathrm{Cu}$ liquid alloys: measurement and thermodynamic description. J Mater Sci 47:8145-8152. https://doi.org/10. 1007/s10853-012-6710-x

[21] Dahlborg U, Besser M, Calvo-Dahlborg M et al (2007) Diffusion of $\mathrm{Cu}$ in $\mathrm{AlCu}$ alloys of different composition by quasielastic neutron scattering. $J$ Non Cryst Solids 353:3295-3299. https://doi.org/10.1016/j.jnoncrysol.2007. 05.074

[22] Zhang B, Griesche A, Meyer A (2010) Diffusion in Al-Cu melts studied by time-resolved X-Ray radiography. Phys Rev Lett 104:35902. https://doi.org/10.1103/PhysRevLett. 104.035902

[23] Trybula M, Jakse N, Gasior W et al (2015) Thermodynamics and concentration fluctuations of liquid $\mathrm{Al}-\mathrm{Cu}$ and $\mathrm{Al}-\mathrm{Zn}$ alloys. Arch Metall Mater 60:649-655. https://doi.org/10. 1515/amm-2015-0187

[24] Tanaka T, Gokcen N, Spencer P (1993) Evaluation of interaction parameters in dilute liquid ternary alloys by a solution model based on the free volume theory. Z Metallkd 84:100-105

[25] Trybula M, Gancarz T, Gasior W, Pasturel A (2014) Bulk and surface properties of liquid $\mathrm{Al}-\mathrm{Li}$ and $\mathrm{Li}-\mathrm{Zn}$ alloys. Metall Mater Trans A Phys Metall Mater Sci. https://doi.org/ 10.1007/s11661-014-2524-6

[26] Novakovic R, Tanaka T, Muolo ML et al (2005) Bulk and surface properties of liquid $\mathrm{Ag}-\mathrm{X}(\mathrm{X}=\mathrm{Ti}, \mathrm{Hf})$ compound forming alloys. Surf Sci 591:56-69. https://doi.org/10.1016/ j.susc.2005.06.022

[27] Dzugutov M (1996) A universal scaling law for atomic diffusion in condensed matter. Nature 381:137-139. https:// doi.org/10.1038/35079655

[28] Chapman C, Cowling TG (1970) The mathematical theory of non-uniform gases. Cambridge University Press, London

[29] Bhatia AB, Singh RN (1982) Thermodynamic properties of compound forming molten alloys in a weak interaction approximation. Phys Chem Liq 11:343-351. https://doi.org/ 10.1080/00319108208080755

[30] Prasad LC, Jha RK (2005) Surface tension and viscosity of Sn-based binary liquid alloys. Phys status solidi 202:2709-2719. https://doi.org/10.1002/pssa.200520080

[31] Prasad L, Singh R (1991) Surface segregation and concentration fluctuations at the liquid-vapor interface of molten Cu-Ni alloys. Phys Rev B 44:13768-13771. https://doi.org/ 10.1103/PhysRevB.44.13768

[32] Bhatia A, Hargrove W, Thornton D (1974) Concentration fluctuations and partial structure factors of compound- forming binary molten alloys. Phys Rev B 9:435-444. https://doi.org/10.1103/PhysRevB.9.435

[33] Warren BE (1969) X-ray diffraction. Addison-Wesley, Reading

[34] Bhatia AB, Singh RN (1982) Short range order and concentration fluctuations in regular and compound forming molten alloys. Phys Chem Liq 11:285-313. https://doi.org/ 10.1080/00319108208080752

[35] Brillo J, Bytchkov A, Egry I et al (2006) Local structure in liquid binary $\mathrm{Al}-\mathrm{Cu}$ and $\mathrm{Al}-\mathrm{Ni}$ alloys. J Non Cryst Solids 352:4008-4012. https://doi.org/10.1016/j.jnoncrysol.2006. 08.011

[36] Plimpton SJ (1995) Fast parallel algorithms for short-range molecular dynamics. J Comput Phys 117:1-19. https://doi. org/10.1006/jcph.1995.1039

[37] Brillo J, Egry I, Ho I (2006) Density and thermal expansion of liquid $\mathrm{Ag}-\mathrm{Cu}$ and $\mathrm{Ag}-\mathrm{Au}$ Alloys. 27:494-506. https:// doi.org/10.1007/s10765-005-0011-4

[38] Rycroft C (2009) Voro ++: a three-dimensional Voronoi cell library in $\mathrm{C}++$. Chaos 19:41111. https://doi.org/10.1063/1. 3215722

[39] Darken L (1948) Diffusion, mobility and their interrelation through free energy in binary metallic systems. Trans Met Soc Aime 175:184

[40] Jacucci G, McDonald I (1980) Collective excitations in a liquid alloy. J Phys F: Met Phys 10:L15-L19. https://doi.org/ 10.1088/0305-4608/10/1/003

[41] Redlich O, Kister AT (1948) Algebraic representation of thermodynamic properties and the classification of solutions. Ind Eng Chem 40:345-348. https://doi.org/10.1021/ ie $50458 \mathrm{a} 036$

[42] Harris KR (2009) The fractional Stokes-Einstein equation: application to Lennard-Jones, molecular, and ionic liquids. J Chem Phys 131:54503. https://doi.org/10.1063/1.3183951

[43] Hoover WG, Evans DJ, Hickman RB et al (1980) LennardJones triple-point bulk and shear viscosities. Green-Kubo theory, Hamiltonian mechanics, and nonequilibrium molecular dynamics. Phys Rev A 22:1690-1697. https://doi.org/ 10.1103/PhysRevA.22.1690

[44] Witusiewicz VT, Hecht U, Fries SG, Rex S (2004) The AgAl-Cu system. J Alloys Compd 385:133-143. https://doi. org/10.1016/j.jallcom.2004.04.126

[45] Kargl F, Weis H, Unruh T, Meyer A (2012) Self diffusion in liquid aluminium. J Phys: Conf Ser 340:12077. https://doi. org/10.1088/1742-6596/340/1/012077

[46] Meyer A (2010) Self-diffusion in liquid copper as seen by quasielastic neutron scattering. Phys Rev B Condens Matter Mater Phys 81:2009-2011. https://doi.org/10.1103/Phys RevB.81.012102 
[47] Bhatia A, Hargrove W (1974) Concentration fluctuations and thermodynamic properties of some compound forming binary molten systems. Phys Rev B 10:3186-3196. https://doi. org/10.1103/PhysRevB.10.3186

[48] Brillo J, Chathoth SM, Koza MM, Meyer A (2008) Liquid $\mathrm{Al}_{80} \mathrm{Cu}_{20}$ : atomic diffusion and viscosity. Appl Phys Lett 93:121905. https://doi.org/10.1063/1.2977863

[49] Ojwang' JGO, Van Santen R, Kramer GJ, et al (2008) Predictions of melting, crystallization, and local atomic arrangements of aluminum clusters using a reactive force field. J Chem Phys. https://doi.org/10.1063/1.3050278

[50] Pasturel A, Jakse N (2015) On the role of entropy in determining transport properties in metallic melts. J Phys Condens Matter 27:325104. https://doi.org/10.1088/0953-8984/ 27/32/325104

[51] Saw CK, Schwarz RB (1988) Chemical short-range order parameter in dense random-packed models. J Less Common Met 140:385-393. https://doi.org/10.1016/0022-5088(88) 90399-2

[52] Das SK, Horbach J, Koza MM et al (2005) Influence of chemical short-range order on atomic diffusion in Al-Ni melts. Appl Phys Lett 86:11918. https://doi.org/10.1063/1. 1845590

[53] Protopapas P, Andersen HC, Parlee NAD (1973) Theory of transport in liquid metals. I. Calculation of self-diffusion coefficients. J Chem Phys 59:15. https://doi.org/10.1063/1. 1679784

[54] Foffi G, Götze W, Sciortino F et al (2003) Mixing effects for the structural relaxation in binary hard-sphere liquids. Phys Rev Lett 91:85701. https://doi.org/10.1103/PhysRevLett.91. 085701

[55] Trybula M (2015) Thermodynamic, structural and thermophysical properties of liquid Al-Li-Zn alloys, Ph.D. Thesis, 2015 IMMS PAS

[56] Stukowski A (2012) Structure identification methods for atomistic simulations of crystalline materials. Model Simul Mater Sci Eng 20:45021-1-45021-18. https://doi.org/10. $1088 / 0965-0393 / 20 / 4 / 045021$
[57] Yu HB, Samwer K, Wang WH, Bai HY (2013) Chemical influence on $\beta$-relaxations and the formation of moleculelike metallic glasses. Nat Commun 4:1-6. https://doi.org/10. 1038/ncomms3204

[58] Yu HB, Samwer K, Wu Y, Wang WH (2012) Correlation between $\beta$ relaxation and self-diffusion of the smallest constituting atoms in metallic glasses. Phys Rev Lett 109:1-5. https://doi.org/10.1103/PhysRevLett.109.095508

[59] Yu H, Wang W, Samwer K (2013) The $\beta$ relaxation in metallic glasses: an overview. Mater Today 16:6-20. https:// doi.org/10.1016/j.mattod.2013.05.002

[60] Angell CA (1995) Formation of glasses from liquids and biopolymers. Science 267:1924-1935. https://doi.org/10. 1126/science.267.5206.1924

[61] Hoyt J, Asta M, Sadigh B (2000) Test of the universal scaling law for the diffusion coefficient in liquid metals. Phys Rev Lett 85:594-597. https://doi.org/10.1103/Phys RevLett.85.594

[62] Angell C (1991) Relaxation in liquids, polymers and plastic crystals - strong/fragile patterns and problems. J Non Cryst Solids 131-133:13-31. https://doi.org/10.1016/00223093(91)90266-9

[63] Debenedetti P, Stillinger F (2001) Supercooled liquids and the glass transition. Nature 410:259-267. https://doi.org/10. $1038 / 35065704$

[64] Eskin D, Du Q, Ruvalcaba D, Katgerman L (2005) Experimental study of structure formation in binary $\mathrm{Al}-\mathrm{Cu}$ alloys at different cooling rates. Mater Sci Eng, A 405:1-10. https:// doi.org/10.1016/j.msea.2005.05.105

[65] Dong HB, Lee PD (2005) Simulation of the columnar-toequiaxed transition in directionally solidified $\mathrm{Al}-\mathrm{Cu}$ alloys. Acta Mater 53:659-668. https://doi.org/10.1016/j.actamat. 2004.10.019

[66] Gill SC, Kurz W (1993) Rapidly solidified AlCu alloys-I. experimental determination of the microstructure selection map. Acta Metall Mater 41:3563-3573. https://doi.org/10. 1016/0956-7151(93)90237-M 